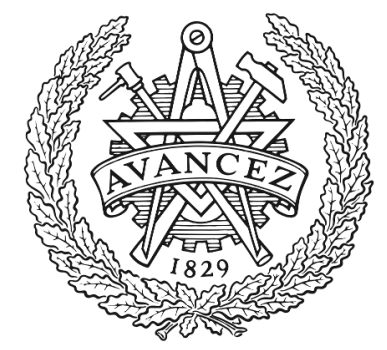

CHALMERS

UNIVERSITY OF TECHNOLOGY

\title{
Transient isomers in the photodissociation of bromoiodomethane
}

Downloaded from: https://research.chalmers.se, 2023-04-26 12:25 UTC

Citation for the original published paper (version of record):

Marcellini, M., Nasedkin, A., Zietz, B. et al (2018). Transient isomers in the photodissociation of bromoiodomethane. Journal of Chemical Physics, 148(13). http://dx.doi.org/10.1063/1.5005595

N.B. When citing this work, cite the original published paper. 


\title{
Transient isomers in the photodissociation of bromoiodomethane
}

\author{
Moreno Marcellini, ${ }^{1,2,3,4, a)}$ Alexandr Nasedkin, ${ }^{1,5}$ Burkhard Zietz, ${ }^{1}$ Jonas Petersson, ${ }^{1}$ \\ Jonathan Vincent, ${ }^{1}$ Federico Palazzetti, ${ }^{6}$ Erik Malmerberg, ${ }^{7,8}$ Qingyu Kong, ${ }^{9,10}$ \\ Michael Wulff, ${ }^{10}$ David van der Spoel, ${ }^{2}$ Richard Neutze,${ }^{7}$ and Jan Davidsson ${ }^{1, b)}$ \\ ${ }^{1}$ Department of Chemistry-Ångström Laboratory, Uppsala University, P.O. Box 462, \\ SE-751 20 Uppsala, Sweden \\ ${ }^{2}$ Department of Cell and Molecular Biology, Uppsala University, Husargatan 3, P.O. Box 596, \\ SE-751 24 Uppsala, Sweden \\ ${ }^{3}$ Ceramic Synthesis and Functionalization Lab, UMR3080 CNRS/Saint-Gobain, 84306 Cavaillon, France \\ ${ }^{4}$ Institut UTINAM-UMR 6213 CNRS, Université Bourgogne Franche-Comté, 16 Route de Gray, \\ F-25030 Besançon, France \\ ${ }^{5}$ Department of Physics, Chalmers University of Technology, SE-412 96 Gothenburg, Sweden \\ ${ }^{6}$ Universitá di Perugia, Dipartimento di Chimica, Biologia e Biotecnologie, 06123 Perugia, Italy \\ ${ }^{7}$ Department of Chemistry and Molecular Biology, University of Gothenburg, SE-405 30 Gothenburg, Sweden \\ ${ }^{8}$ AstraZeneca, Pepparedsleden 1, SE-431 50 Mölndal, Gothenburg, Sweden \\ ${ }^{9}$ Argonne National Laboratory's, Xray Science Division, 9700 S Cass Ave., Argonne, Illinois 60439, USA \\ ${ }^{10}$ European Synchrotron Radiation Facility, B.P. 220, F-380 43 Grenoble Cedex, France
}

(Received 19 September 2017; accepted 14 March 2018; published online 4 April 2018)

The photochemistry of halomethanes is fascinating for the complex cascade reactions toward either the parent or newly synthesized molecules. Here, we address the structural rearrangement of photodissociated $\mathrm{CH}_{2} \mathrm{IBr}$ in methanol and cyclohexane, probed by time-resolved $\mathrm{X}$-ray scattering in liquid solution. Upon selective laser cleavage of the $\mathrm{C}-\mathrm{I}$ bond, we follow the reaction cascade of the two geminate geometrical isomers, $\mathrm{CH}_{2} \mathrm{I}-\mathrm{Br}$ and $\mathrm{CH}_{2} \mathrm{Br}-\mathrm{I}$. Both meta-stable isomers decay on different time scales, mediated by solvent interaction, toward the original parent molecule. We observe the internal rearrangement of $\mathrm{CH}_{2} \mathrm{Br}-\mathrm{I}$ to $\mathrm{CH}_{2} \mathrm{I}-\mathrm{Br}$ in cyclohexane by extending the time window up to $3 \mu \mathrm{s}$. We track the photoproduct kinetics of $\mathrm{CH}_{2} \mathrm{Br}-\mathrm{I}$ in methanol solution where only one isomer is observed. The effect of the polarity of solvent on the geminate recombination pathways is discussed. Published by AIP Publishing. https://doi.org/10.1063/1.5005595

\section{INTRODUCTION}

A typical photochemical reaction is initiated by the absorption of light by a molecule which goes in an excited state and generally fragments. From these states, the reaction can proceed via one or several short-lived intermediate states and end with some product in the ground state. While being stable molecules, the original and final products can be structurally different. Owing to the fragmentation of the parent molecules, the solvent-caged geminate recombinations of the fragments are generally faster than the non-geminate ones, which take place at longer time scale. If the geminate recombination reaction produces metastable molecules, such as isomers or complexes, then the lifetime of these transient molecules are significantly long, on the order of nanoseconds.

One way to resolve the molecular structural rearrangements and intermediate states during a photochemical reaction is to use Time-Resolved Wide Angle X-ray Scattering (TRWAXS) ${ }^{1-6}$ which has emerged as a powerful technique for observing the structure and kinetics of transient photochemical

a)Electronic mail: moreno.marcellini@yahoo.it

b)Electronic mail: jan.davidsson@kemi.uu.se intermediates in solution, from small molecules containing some heavier atoms to biological macromolecules. For example, the kinetics of the photo-initiated reactions have been studied for $\mathrm{HgI}_{2}$ in methanol, ${ }^{7} \mathrm{CHI}_{3}$ in methanol ${ }^{8}$ and cyclohexane, ${ }^{9} \mathrm{CBr}_{4}$ in methanol, ${ }^{10} \mathrm{CH}_{2} \mathrm{I}_{2}$ in methanol and in cyclohexane, ${ }^{11,12} \mathrm{I}_{2}$ in $\mathrm{CCl}_{4}{ }^{13-15}$ and in methanol, ${ }^{16} \mathrm{Br}_{2}$ in $\mathrm{CCl}_{4},{ }^{17}$ and $\mathrm{I}_{3}{ }^{-}$in methanol, water, and acetonitrile. ${ }^{18,19}$ The structural changes in hemeproteins, ${ }^{20-25}$ various proton pumping membrane proteins, ${ }^{26-30}$ photosynthetic groups ${ }^{31}$ and lipidic multilayers, ${ }^{32}$ and gold trimer complexation ${ }^{33}$ have been resolved. Variations of the density of the solvent during thermal expansion are also followed in real time, ${ }^{13,34-36}$ and intramolecular displacements of the solvent atoms of few hundredths of $\AA$ have been inferred. ${ }^{13,14,37-39}$ TR-WAXS is a valuable complement to time-resolved spectroscopy because it provides structural information on the reaction transient intermediates, although such structures are based on quantum chemistry calculations to determine the in vacuo topology of the possible intermediate, and on molecular dynamic (MD) simulations to determine the topology in solvent.

The photochemistry of organo-halides ${ }^{40}$ is of strong interest in atmospheric chemistry due to their ozone depletion ability in the stratosphere. ${ }^{41-43}$ In particular, dihalomethanes have been recognized as potentially important since they are naturally emitted into the atmosphere as bio-products of 
several terrestrial and marine living beings ${ }^{44-49}$ with an apparently puzzling chemistry. ${ }^{50-53}$ Dihalomethanes are used in many synthesis reactions: ultraviolet photolysis of $\mathrm{CH}_{2} \mathrm{I}_{2}$ and $\mathrm{CHI}_{3}$ in solutions is widely used for photocyclopropanation of alkanes via $\mathrm{CH}_{2} \mathrm{I}-\mathrm{I}$ or $\mathrm{CHI}_{2}-\mathrm{I} .{ }^{54-60}$ Bromoiodomethane, $\mathrm{CH}_{2} \mathrm{IBr}$, with two different carbon halogen bonds, is the prototype to study bond selective excitation ${ }^{61-63}$ and optical control of bond cleavage. ${ }^{64,65}$ Various computational studies ${ }^{66-68}$ on $\mathrm{CH}_{2} \mathrm{IBr}$ have prompted us to investigate the possibility to optically control certain reactions. Organo-halides, containing some heavy scattering atoms such as either bromine or iodine, are small molecules whose photoreactions function as a benchmark to determine the time and spatial resolution of TR-WAXS.

Di-iodomethane, $\mathrm{CH}_{2} \mathrm{I}_{2}$, is closely related to $\mathrm{CH}_{2} \mathrm{IBr}$, and its photochemistry in solution is characterized by the geminate formation of an ns-transient isomer, $\mathrm{CH}_{2} \mathrm{I}-\mathrm{I}$. The former isomer identification and the reaction mechanisms of the photofragments outside the solvent cage were originally determined in acetonitrile by femto-seconds pump-probe spectroscopy by Tarnovsky et al. ${ }^{69}$ on the basis of the similarity of the observed product absorption spectra to those one previously observed in cold matrices by Maier et al. ${ }^{70,71}$ The cited absorption spectroscopy results were promptly confirmed by Zheng et al. ${ }^{72}$ at ns-time scale and Kwok et al. ${ }^{73}$ at ps-time scales. More recent experiments, made in the TR-WAXS framework both in polar (methanol) and in non-polar (cyclohexane) solvents, confirmed the photoreaction schemes in the ns-time scale albeit the lifetime of the transient isomer $\mathrm{CH}_{2} \mathrm{I}-\mathrm{I}$ was significantly different in the two solvents. ${ }^{11,12}$ Tarnovsky et al. ${ }^{58}$ came to similar conclusions for analogous photoreactions in $n$-hexane, dichloromethane, methanol, and ethanol.

The photochemistry in solution of bromoiodomethane, $\mathrm{CH}_{2} \mathrm{IBr}$, seems to be similar, but significantly more complicated due to the two different halogens. ${ }^{74}$ In the gas phase, $\mathrm{CH}_{2} \mathrm{IBr}$ exhibits two prominent UV absorption bands: excitation of the A-band around 260-270 nm favors C-I bond cleavage; excitation of the $\mathrm{B}$-band around $220 \mathrm{~nm}$ favors $\mathrm{C}-\mathrm{Br}$ bond cleavage. Similarly, the cleavage energies for the $\mathrm{C}-\mathrm{Br}$ and $\mathrm{C}-\mathrm{I}$ bonds hold in gas phases for the more complex photoinitiated dissociation reaction of the analogous bromobutane. ${ }^{75,76}$ The same observations hold in solution phase. ${ }^{72,73,77-80}$

Either Kwok et al..$^{73}$ and Zheng and Phillips ${ }^{77}$ pointed out that $\mathrm{CH}_{2} \mathrm{Br}-\mathrm{I}$, which is observed in cyclohexane, could undergo an intramolecular reorganization to form a second geometrical isomer $\mathrm{CH}_{2} \mathrm{I}-\mathrm{Br}$; see the reaction scheme in Fig. 1. Quantum mechanical (QM) calculations assign a $2.7 \mathrm{kcal} / \mathrm{mol}$ lower energy to $\mathrm{CH}_{2} \mathrm{I}-\mathrm{Br}$ than to $\mathrm{CH}_{2} \mathrm{Br}-\mathrm{I}$, ${ }^{68}$ hinting to $\mathrm{CH}_{2} \mathrm{I}-\mathrm{Br}$ as metastable intermediate of the ground state relaxation cascade to $\mathrm{CH}_{2} \mathrm{IBr}$. To identify a possible pathway between $\mathrm{CH}_{2} \mathrm{Br}-\mathrm{I}$ and $\mathrm{CH}_{2} \mathrm{I}-\mathrm{Br}$, new quantum chemistry calculations in the framework of CASPT2 were done. ${ }^{74}$ We searched for a conical intersection in the energy landscape corresponding to a transition between the two isomers. Unfortunately we did not find any solution.

Albeit thermodynamical considerations favor the formation of $\mathrm{CH}_{2} \mathrm{I}-\mathrm{Br}$ from $\mathrm{CH}_{2} \mathrm{Br}-\mathrm{I}$, this fact is questionable from the point of view of transition state quantum chemistry calculations.

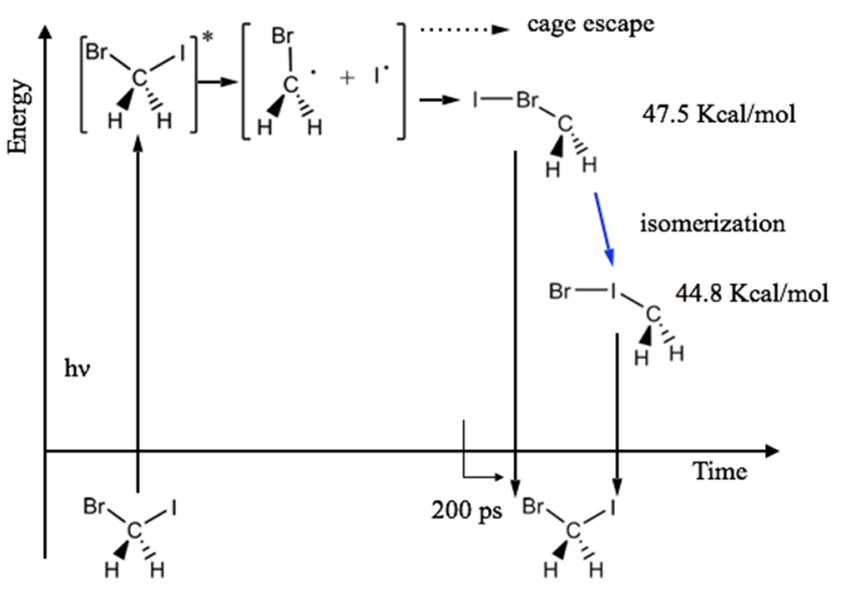

FIG. 1. Reaction cascade: following UV excitation of $\mathrm{CH}_{2} \mathrm{IBr}$, the photofragments partially recombine to form $\mathrm{CH}_{2} \mathrm{Br}-\mathrm{I}$ that converts later to $\mathrm{CH}_{2} \mathrm{IBr}$. The interconversion between $\mathrm{CH}_{2} \mathrm{Br}-\mathrm{I}$ and $\mathrm{CH}_{2} \mathrm{I}-\mathrm{Br}$ (blue arrow) is thermodynamically favorable. Any reaction involving I is not considered here. Values indicating isomer difference in energy versus the ground state are taken from Liu et al. ${ }^{68}$ Axes are not to scale.

Previous investigations carried out by femtosecond transient absorption spectroscopy ${ }^{78-80}$ and nanosecond and picosecond transient resonance Raman spectroscopy $72,73,77$ have indicated that two different isomers, $\mathrm{CH}_{2} \mathrm{I}-\mathrm{Br}$ and $\mathrm{CH}_{2} \mathrm{Br}-\mathrm{I}$, are formed by a geminate recombination in the solution phase. In a ns-transient resonance Raman study in cyclohexane, Zheng and Phillips ${ }^{77}$ observed the formation of $\mathrm{CH}_{2} \mathrm{I}-\mathrm{Br}$ following A- and B-band cleavage. Furthermore, the same authors observed the formation of $\mathrm{CH}_{2} \mathrm{Br}-\mathrm{I}$ decaying on a time scale of a few nanoseconds, thus explaining the absence of the $\mathrm{CH}_{2} \mathrm{Br}-\mathrm{I}$ isomer on a longer ns-time-resolved Raman experiment. The remaining question was whether $\mathrm{CH}_{2} \mathrm{I}-\mathrm{Br}$ is formed initially by the geminate recombination or via isomerization of the initially formed $\mathrm{CH}_{2} \mathrm{Br}-\mathrm{I}$.

Tarnovsky et al. ${ }^{78}$ observed the formation of the $\mathrm{CH}_{2} \mathrm{Br}-\mathrm{I}$ following excitation in the A-band in a femtosecond transient absorption experiment in acetonitrile (lifetime $2.5 \mathrm{~ns}$ ). Tang et al. ${ }^{79}$ demonstrated that in 2-butanol $\mathrm{CH}_{2} \mathrm{Br}-\mathrm{I}$ was the only photo-product formed after excitation in the A-band. However, they stated that there might be indications of the formation of another photo-product on a ns-time scale. They also performed two photon excitation experiments at $395 \mathrm{~nm}$ and $405 \mathrm{~nm}$ and observed a significant change in the relative photo-product yields of the two isomers.

The photolysis of $\mathrm{CH}_{2} \mathrm{IBr}$ and other dihalomethanes in water/acetonitrile and saltwater/acetonitrile at $266 \mathrm{~nm}$ has been investigated by ps-time-resolved resonance Raman spectroscopy: ${ }^{81,82}$ only the fingerprints of $\mathrm{CH}_{2} \mathrm{Br}-\mathrm{I}$ were found, with decay times from $\approx 2.3 \mathrm{~ns}$ in acetonitrile to $\approx 0.1 \mathrm{~ns}$ in a solution of $75 \%$ of water and $25 \%$ of acetonitrile. In fact, polarity and proticity of water allow us to eliminate the $\mathrm{CH}_{2} \mathrm{Br}-\mathrm{I}$ to $\mathrm{HI}$ and $\mathrm{HBr}$ acids, and to produce methanediol $\left[\mathrm{CH}_{2}(\mathrm{OH})_{2}\right]$ by water catalyzed $\mathrm{OH}$ insertion.

Anderson et al. ${ }^{83}$ used ultrafast transient absorption spectroscopy of UV photoexcited $\mathrm{CH}_{2} \mathrm{IBr}$ in a series of four solvents (from apolar to polar), and captured the photochemical process involving $\mathrm{CH}_{2} \mathrm{IBr}$ in cyclohexane. In their analysis, both isomers are assumed at time zero. Two decay 
channels were observed for $\mathrm{CH}_{2} \mathrm{Br}-\mathrm{I}$ : $90 \%$ decays to the ground state, whereas the remnant first gives rise to the metastable isomer $\mathrm{CH}_{2} \mathrm{I}-\mathrm{Br}$ that subsequently relaxes to the ground state. The lifetime of $\mathrm{CH}_{2} \mathrm{Br}-\mathrm{I}$ was estimated to be $1.4 \mathrm{~ns}$, which is comparable with the lifetime of $\mathrm{CH}_{2} \mathrm{Br}-\mathrm{I}$ in acetonitrile.

In this report, we yield novel insights into the complex photochemistry of $\mathrm{CH}_{2} \mathrm{IBr}$ in cyclohexane and methanol. We show how the reaction cascade from the photo-excited state follows different paths in two solvents. Our reaction scheme and kinetics model are corroborated by Quantum Mechanical (QM) and Molecular Dynamic (MD) calculations. In this way, we can follow the photochemistry of $\mathrm{CH}_{2} \mathrm{IBr}$ as seen by X-ray scattering by extending the analysis in timedelays not yet explored by both UV-VIS and IR spectroscopy methods.

\section{EXPERIMENT AND METHODS}

\section{A. X-ray data collection}

$\mathrm{X}$-ray data collection was carried out at the dedicated time-resolved beamline ID09B at the European Synchrotron Radiation Facility (ESRF) by employing a pump-probe collection scheme with laser-off and laser-on measurements as the same way as in a similar experiment. ${ }^{12}$

Samples consisted of $20 \mathrm{mM}$ of $\mathrm{CH}_{2} \mathrm{IBr}(99 \%$, stabilized, Arcos Organics) dissolved in either methanol (99.5\%, Arcos Organics), corresponding to 1235 solvent molecules per solute molecule or in cyclohexane (99.5\%, Arcos Organics) corresponding to 460 solvent molecules per solute molecule. Samples were pumped through a sapphire nozzle creating a stable flat jet with a thickness of approximately $300 \mu \mathrm{m}$. The total volume of each solution was $300 \mathrm{ml}$, ensuring that the contributions from products throughout the experiments were negligible.

The solutions were excited with an ultraviolet laser pulse ( $\lambda=267 \mathrm{~nm}, E=40 \mu \mathrm{J}$, and $2 \mathrm{ps}$ in duration) focused to a spot of approximately $160 \mu \mathrm{m}$ in diameter and aligned to a position of a few $\mathrm{mm}$ from the nozzle and subsequently probed by scattering from an X-ray pink beam ${ }^{84}$ pulse $(\Delta E / E=3 \%$, $E=17 \mathrm{keV}, I_{0} \sim 10^{9}$ photons, and $\tau=100 \mathrm{ps}$ in duration) after an electronically set time-delay $\Delta t$, after the laser flash, in the range of $0.2 \mathrm{~ns}$ to about $3 \mu \mathrm{s}$ (laser-on). Measurements at negative time-delay $\Delta t=-3 \mathrm{~ns}$ were used to assure for any X-ray intensity drift (laser-off) and to measure the sample in equilibrium. Scattered X-rays were recorded on a two dimensional charge coupled device (MarCCD) and processed using FIT2D. ${ }^{85,86}$ The pump-probe sequence was repeated at $1000 \mathrm{~Hz}$, and each image was exposed for $10 \mathrm{~s}$. The flow rate of the jet was sufficiently high to provide fresh sample for each pump-probe cycle.

To monitor the temporal changes in solution, the differential intensity was computed by subtracting the laser-off scattering from the laser-on scattering recorded at a specified $\Delta t$. After rejection of outliers, 10-20 two-dimensional scattering datasets were averaged to improve the signal-tonoise ratio. The difference signal has also been corrected for polychromaticity of the X-ray beam.

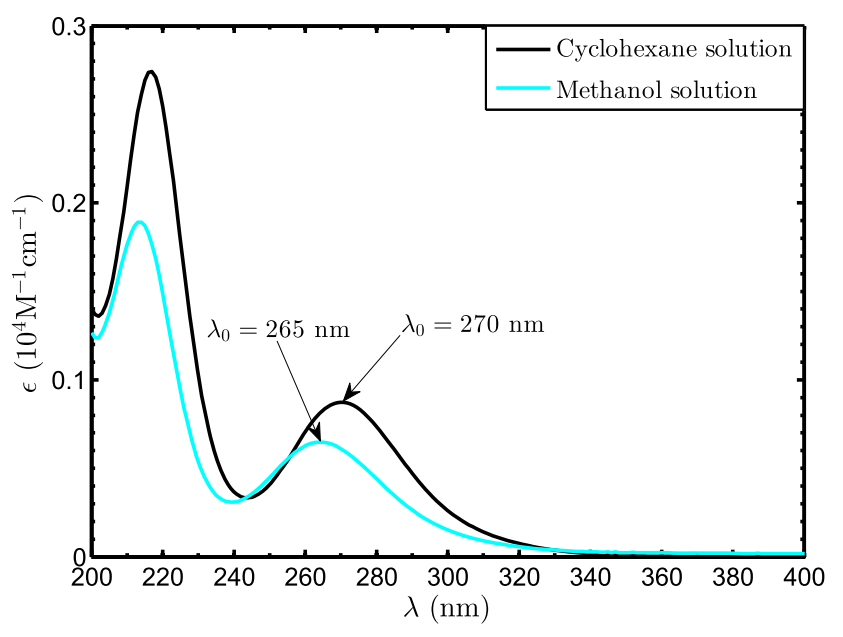

FIG. 2. Extinction coefficient spectra of $\mathrm{CH}_{2} \mathrm{IBr}$ in methanol and cyclohexane solution. The solvent causes a shift in the absorption peak at both the $\mathrm{C}-\mathrm{Br}$ and $\mathrm{C}-\mathrm{I}$ chromophores with respect to the gas phase.

\section{B. Absorption spectroscopy on $\mathrm{CH}_{2} \mathrm{IBr}$}

Absorption spectroscopy measurements of the same solutions were performed in a Cary 5000 (Varian) spectrometer. The results are shown in Fig. 2. The collected spectra were deconvoluted in three Gaussians for each of the two absorption bands as done before. ${ }^{65,78}$ In particular, it is widely accepted that the A- and B-bands are the results of three overlapping electronic transitions, from the ground state to the ${ }^{3} Q_{1},{ }^{3} Q_{0}$, ${ }^{1} Q_{1}$ excited states, with increasing energies and localized on $n_{I} \rightarrow \sigma_{\mathrm{C}-\mathrm{I}}^{\star}$ and $n_{\mathrm{Br}} \rightarrow \sigma_{\mathrm{C}-\mathrm{Br}}^{\star}$, respectively.

In Fig. 2, it can be observed that the solvent shifts the absorption peak at both the $\mathrm{C}-\mathrm{Br}$ and $\mathrm{C}-\mathrm{I}$ chromophores with respect to the gas phase. ${ }^{61,83}$ In particular, the absorption in cyclohexane is red-shifted, whereas in methanol it is blue shifted. Such behavior is influenced by the different polarities of the solvents. ${ }^{83}$

Results of six Gaussians' fitting (not reported here) clearly show no contribution of the B-band, neither in cyclohexane nor in methanol, at the wavelength of $\lambda=267 \mathrm{~nm}$. It can be concluded that the formation of the $\mathrm{CH}_{2} \mathrm{I}-\mathrm{Br}$ in the solvent cage just after the UV photodissociation is unlikely. This result also highlights the absence of any kinetics involving $\mathrm{Br}$. Even if there is some natural amount of $\mathrm{Br}_{2}$ molecules, the contribution to the scattering would be negligible and on the limits of sensitivity of the TR-WAXS method. For the same reason, any contribution to the scattering from BrI was neglected in the analysis. ${ }^{83}$

\section{Structural calculations of reactants and photo-products}

The in vacuo optimization of geometrical structures of $\mathrm{CH}_{2} \mathrm{IBr}, \mathrm{CH}_{2} \mathrm{I}-\mathrm{Br}$, and $\mathrm{CH}_{2} \mathrm{Br}-\mathrm{I}$ was performed at the DFT/B3LYP level of theory using the Gaussian03 program. ${ }^{87}$ The aug-cc-pVQZ basis set was used to optimize the structure for $\mathrm{H}, \mathrm{C}$, and $\mathrm{Br}$ atoms, whereas aug-cc-pVQZ-pp basis set functions were used for I atom. The results of structure optimization and frequency calculations were used to parametrize the molecules in the framework of the Optimized Potentials 
for Liquid Simulations (OPLS) ${ }^{88,89}$ force field inter-atomic interaction approximation, specifically designed for liquids, to create the topology for successive Molecular Dynamic (MD) simulations.

Gromacs 4.6.3 $3^{90-94}$ was used to perform the MD simulations. Briefly, no atomic bond constraints were applied in the simulations, and the temperature was set to $300 \mathrm{~K}$. The simulation boxes, whose sides were approximately $24.5 \AA$ for methanol and $34 \AA$ for cyclohexane, contain 216 molecules: one solute molecule $\left(\mathrm{CH}_{2} \mathrm{IBr}, \mathrm{CH}_{2} \mathrm{I}-\mathrm{Br}, \mathrm{CH}_{2} \mathrm{Br}-\mathrm{I}\right.$, or $\mathrm{CH}_{2} \mathrm{Br}$ ) ) and 215 solvent molecules (methanol or cyclohexane) to approximate the experimental solution concentration. After NVT and NPT equilibrations, the simulated time of the individual MD simulation was $4 \mathrm{~ns}$ with $1 \mathrm{fs}$ time steps.

MD simulations were used for checking the influence of solvents on the structure and to compute the radial distribution function of all the interesting molecules. The exclusion of the bond constraints in the MD simulations leads to slight changes of the geometries of the target species in the solvent. In particular, it affects the $\mathrm{I}-\mathrm{C}-\mathrm{Br}, \mathrm{C}-\mathrm{I}-\mathrm{Br}$, and $\mathrm{C}-\mathrm{Br}-\mathrm{I}$ angles by altering the distances between $\mathrm{I}$ and $\mathrm{Br}$ which, being the electronically heaviest atoms, are the proxies in the $\mathrm{X}$ ray scattering to resolve any structural change. The output of $\mathrm{QM}$ calculations and MD simulations for halogene distances in $\mathrm{CH}_{2} \mathrm{IBr}, \mathrm{CH}_{2} \mathrm{I}-\mathrm{Br}$, and $\mathrm{CH}_{2} \mathrm{Br}-\mathrm{I}$ in vacuo and in both solvents is reported in Table I. The atomic distances for $\mathrm{I}_{2}, \mathrm{I}_{2}{ }^{-}$, and $\mathrm{I}_{3}{ }^{-}$species are instead taken from previous experimental results. $^{12}$

We used the results of the MD simulations to calculate the radial distribution function $g_{i j}(r)$, defined as

$$
g_{i j}(r)=\frac{\left\langle\rho_{j}(r)\right\rangle}{\left\langle\rho_{j}\right\rangle_{l o c a l}},
$$

where $\left\langle\rho_{j}(r)\right\rangle$ is the density of particle $j$ at the distance $r$ from particle $i$, and $\left\langle\rho_{j}\right\rangle_{\text {local }}$ is the particle density of $j$ integrated over a sphere of infinite radius around particles $i$. The $g_{i j}(r)$ is the input parameter for the calculation of the total X-ray scattering intensity $S$ in liquid solution; see Eq. (3). Beyond this classical modelization, a new method to decipher solution $\mathrm{X}$-ray scattering by using experimentally guided MD simulation has recently become available. ${ }^{95}$

TABLE I. Computed I-Br distances in $\mathrm{CH}_{2} \mathrm{IBr}, \mathrm{CH}_{2} \mathrm{I}-\mathrm{Br}, \mathrm{CH}_{2} \mathrm{Br}-\mathrm{I}$ in vacuo and in the solvents. $\mathrm{CH}_{2} \mathrm{IBr}$ and isomers are let to relax in the solvent during the MD simulation.

\begin{tabular}{lccc}
\hline \hline & Solvent & $\mathrm{r}(\AA)$ Gaussian & $\mathrm{r}(\AA)$ Gromacs \\
\hline \multirow{2}{*}{$\mathrm{CH}_{2} \mathrm{IBr}$} & in vacuo & 3.36 & $\times$ \\
& Cyclohexane & $\times$ & 3.371 \\
& Methanol & $\times$ & 3.377 \\
\hline iso- & in vacuo & 2.889 & $\times$ \\
$\mathrm{CH}_{2} \mathrm{I}-\mathrm{Br}$ & Cyclohexane & $\times$ & 2.885 \\
& Methanol & $\times$ & 2.992 \\
\hline iso- & in vacuo & 2.768 & $\times$ \\
$\mathrm{CH}_{2} \mathrm{Br}-\mathrm{I}$ & Cyclohexane & $\times$ & 2.690 \\
& Methanol & $\times$ & 2.745 \\
\hline \hline
\end{tabular}

\section{Data analysis}

The general expression for the total X-ray scattering intensity in liquid solutions, $S$, as a function of $q$ is written as

$$
\begin{aligned}
S(q)= & \sum_{i} N_{i}^{2} f_{i}(q)^{2}+\sum_{i}^{n} \sum_{i \neq j}^{n} N_{i} N_{j} f_{i}(q) f_{j}(q) \\
& \cdot \int_{V} 4 \pi r^{2} \rho_{0}\left(g_{i j}(r)-1\right) \frac{\sin q r}{q r} \mathrm{~d} V,
\end{aligned}
$$

where $f_{i}(q)$ is the atomic scattering form factor, $n$ is the total number of chemical elements in the sampling volume $V, N_{i}$ and $N_{j}$ are the number of $i$ th and $j$ th types of atoms, $\rho_{0}$ is the average density of the sample, and $g_{i j}(r)$ is the radial distribution function defined by Eq. (1).

Diffuse scattering from a liquid solution is a linear combination of three scattering terms: solvent-solvent scattering $S_{\text {solv }}$, solute-solute scattering $S_{\text {sol }}$, and a cross term related to the solute-solvent scattering $S_{\times}$,

$$
S(q)=S_{\text {solv }}(q)+S_{\text {sol }}(q)+S_{\times}(q) .
$$

The largest X-ray scatterers are the molecules that contain $\mathrm{I}$ atoms. In particular, $\mathrm{I}_{3}{ }^{-}$in methanol is the largest one, although it contributes only at the longest time-delay. Among the two possible isomers, both have the same weight in the total scattering, albeit mediated by their concentrations. The total X-ray scattering from the latter two is however different because the bond distances among $\mathrm{Br}$ and I are different between the isomers. The diverse molecular topology causes oscillations at different $q$-points; see, for example, Fig. 3. If we want to list the $\mathrm{X}$-ray scattering cross section from the largest to the smallest observable, then $\mathrm{I}_{3}{ }^{-}>\mathrm{I}_{2}{ }^{-}>\mathrm{I}_{2}>\mathrm{CH}_{2} \mathrm{Br}-\mathrm{I}$ $\approx \mathrm{CH}_{2} \mathrm{I}-\mathrm{Br} .^{96,97}$

Then the experimental difference scattering intensity is given by

$$
\Delta S(q, \Delta t)=\Delta S_{\text {solv }}(q, \Delta t)+\Delta S_{\text {sol }}(q, \Delta t)+\Delta S_{\times}(q, \Delta t),
$$

where $\Delta S_{\text {solv }}(q, \Delta t)$ will be non-zero mainly due to the induced heating in to the system. $\Delta S_{\text {sol }}(q, \Delta t)$ is the solute-only term reflecting changes of the internal structure of the solute molecules. $\Delta S_{\times}(q, \Delta t)$ is the solute-solvent cross term reflecting organization dynamics of the solvent around the solute molecule.

In the low $q$ region, the differential scattering is dominated by a large time-dependent feature that is related to the solvent response to induced heating released in the reaction [Figs. 4(a) and 5(a)]. Two temporal regions can be identified by using Singular Value Decomposition (SVD): ${ }^{98}$ the first region, $\Delta t \geqq 50 \mathrm{~ns}$, is characterized by the non-relaxed heating of the system, whereas the latter, $\Delta t \gtrsim 50 \mathrm{~ns}$, is related to the density change of the hot solvent. ${ }^{34}$ The weak oscillations at $q>3 \AA^{-1}$ in the methanol solution and at $q>2 \AA^{-1}$ in the cyclohexane solution represent the change in molecular composition.

The $\Delta S_{\text {solv }}$ will be treated based on experimental observations for pure solvent, following methods well developed and accepted. . $^{84,99-101}$ The relaxation of spontaneously excited bulk solvent occurs with some time lag. Therefore the 

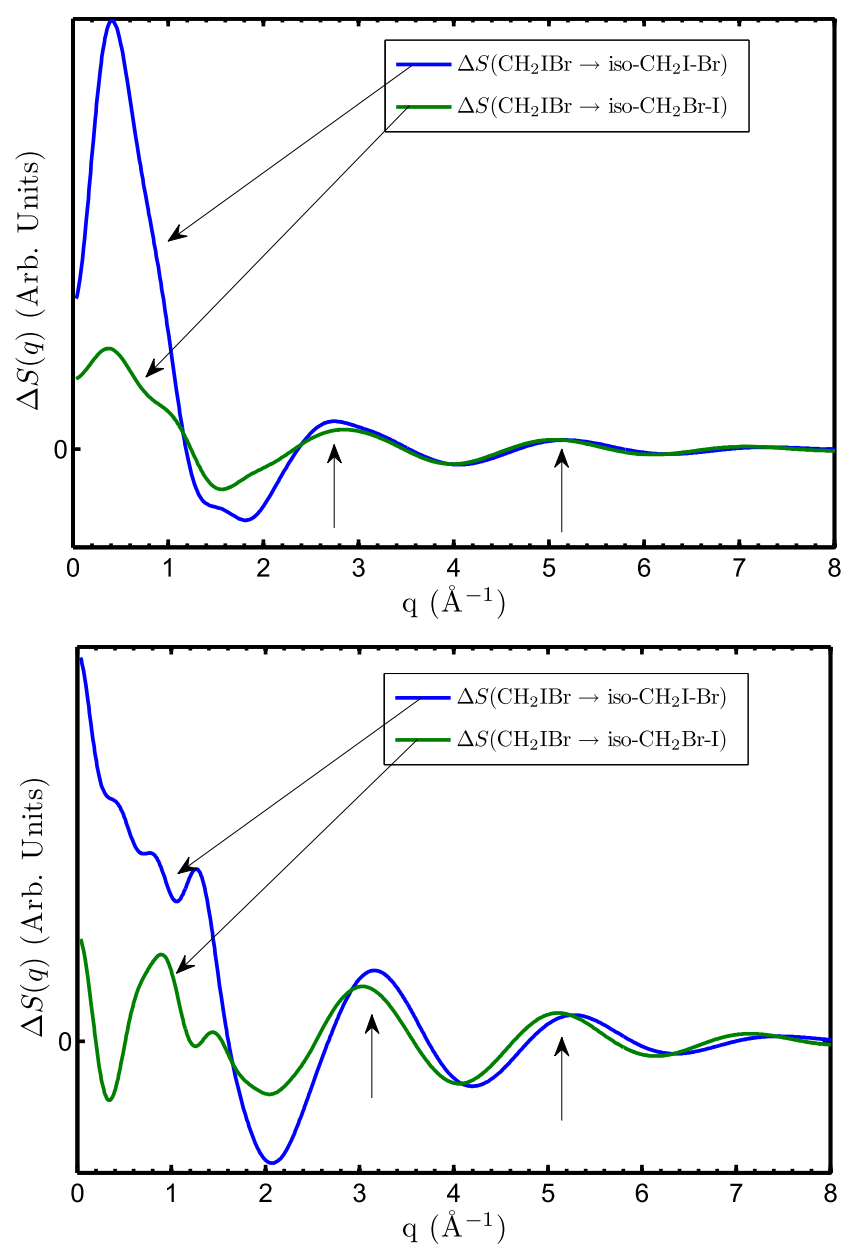

FIG. 3. Examples of computed $\Delta S_{\times}+\Delta S_{\text {sol }}$ for the specified transitions in the case of methanol (top) and cyclohexane (bottom). For $q \lesssim 2.5 \AA^{-1}$, the differential signal $\Delta S$ is dominated by hot solvent expansion. Upward pointing arrows indicate scattering peak positions.

solvent scattering $\Delta S_{\text {solv }}$ term can be linearly expanded in terms of hydrodynamic equation for a liquid, such as

$$
\Delta S_{\text {solv }}(q, \Delta t)=\left(\frac{\partial S}{\partial T}\right)_{\rho} \Delta T(\Delta t)+\left(\frac{\partial S}{\partial \rho}\right)_{T} \Delta \rho(\Delta t)
$$

where $\Delta T(\Delta t)$ and $\Delta \rho(\Delta t)$ are the change of temperature and density, respectively. The two partial derivatives $\left(\frac{\partial S}{\partial T}\right)_{\rho}$ and $\left(\frac{\partial S}{\partial \rho}\right)_{T}$ represent the change in the scattering intensity caused by the temperature change at constant density (valid at short time-delays) and the diffraction intensity change due to expansion of the solution at constant temperature (valid at long time-delay), respectively. ${ }^{34}$ By scaling the experimental solvent components $\left(\frac{\partial S}{\partial T}\right)_{\rho}$ and $\left(\frac{\partial S}{\partial \rho}\right)_{T}$ to the experimental scattering signal at the low q region $\left(0.5<q<1 \AA^{-1}\right)$, the heating signal can be removed from the dataset for the further analysis of molecular rearrangements. The experimentally obtained partial derivatives used in the analysis of the solvent dynamics have been published elsewhere. ${ }^{34,99}$

To compute

$$
\Delta S_{\text {sol }}(q, \Delta t)+\Delta S_{\times}(q, \Delta t)
$$

we have to take all significant reactions into account. Thus, the terms of Eq. (6) were computed for the following reactions:

$$
\begin{aligned}
\mathrm{CH}_{2} \mathrm{I}-\mathrm{Br} & \rightarrow \mathrm{CH}_{2} \mathrm{IBr}, \\
\mathrm{CH}_{2} \mathrm{Br}-\mathrm{I} & \rightarrow \mathrm{CH}_{2} \mathrm{IBr}, \\
\mathrm{CH}_{2} \mathrm{Br} \cdot+\mathrm{I} \cdot & \rightarrow \mathrm{CH}_{2} \mathrm{IBr} .
\end{aligned}
$$

The total theoretical scattering $S(q)$ has to be scaled to the experimental one to determine the scattering from one unit of concentration. The experimental scattering collected at $\Delta t=-3 \mathrm{~ns}$ has been used to determine the scaling constant at the main solvent peak near $1.5-1.7 \AA^{-1}$. The same scaling constant could be applied to the simulated scattering from photoproducts with adjustment for the concentration in computer simulations. Thus, the concentration of the photoproducts could be obtained directly from the fitting. A few examples of simulated scattering differences for the solutes are shown in Fig. 3.

The fitting to the experimental scattering differences has been performed in the $q$-space by minimizing the quantity $\chi^{2}$, defined as

$$
\chi^{2}=\frac{\sum_{i=1}^{n} q_{i}\left(\sum_{j=1}^{k} c_{j} S_{j}\left(q_{i}\right)-S_{\exp }\left(q_{i}\right)\right)^{2}}{n-k-1},
$$

where $n$ is the number of data-points, $k$ is the number of fitting parameters, so $n-k-1$ is the number of degrees of freedom, $c_{j}$ is the fitting coefficient to be optimized, and $S_{j}$ and $S_{\text {exp }}$ are theoretical scattering and experimental scattering, respectively. The multiplication by $q$ amplifies the small signal-to-noise ratio at high $q$ region that is dominated by the fingerprints of the photoproducts. Here we fit each $\Delta S(q, \Delta t)$ finding the smallest $\chi^{2}$ for every $\Delta t$.

The interpretation of the fitting can be complemented with Fourier-analysis of the scattering data, i.e., we compute the sinus-Fourier transform $r \Delta S(r, \Delta t)$ of the experimentally observed differential X-ray scattering given by ${ }^{11,13,14,102}$

$$
\begin{aligned}
r \mathcal{F}(S(q, \Delta t)) & =r \Delta S(r, \Delta t) \\
& =\frac{1}{2 \pi^{2}} \int_{q_{m}}^{q_{M}} q \Delta S(q, \Delta t) \mathrm{e}^{-\beta^{2} q^{2}} \sin (q r) \mathrm{d} q,
\end{aligned}
$$

where $\beta$ is a dumping constant which accounts for the finite domain of the sinus-Fourier transform, and $q_{m}$ and $q_{M}$ define the limits of the integration.

A collection of Fourier transformed scattering Eq. (8) for both solutions is shown in Figs. 4(c) and 5(c) for cyclohexane and methanol, respectively. The $r \mathcal{F}(S(q, \Delta t))$ represents the change in radial electron density averaged over all atoms. However, the transformation might be affected by artifacts due to the integration limits $q_{m}$ and $q_{M}$ in Eq. (8). ${ }^{102}$ Therefore the real space representation is hardly used for an exact calculation of molecular rearrangements, but very helpful to qualitatively identify the trends in the change of electron density.

\section{E. Analytical model}

To draw a simplified kinetics model for the photochemical reactions, it is valuable to include previous knowledge to 
a)

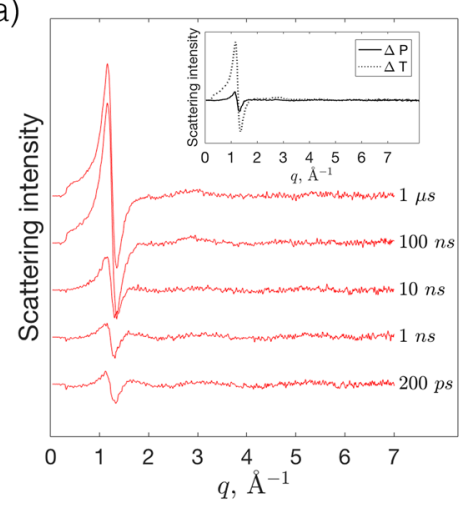

b)

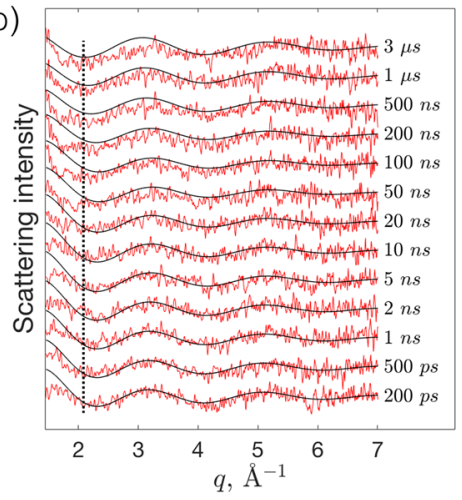

c)
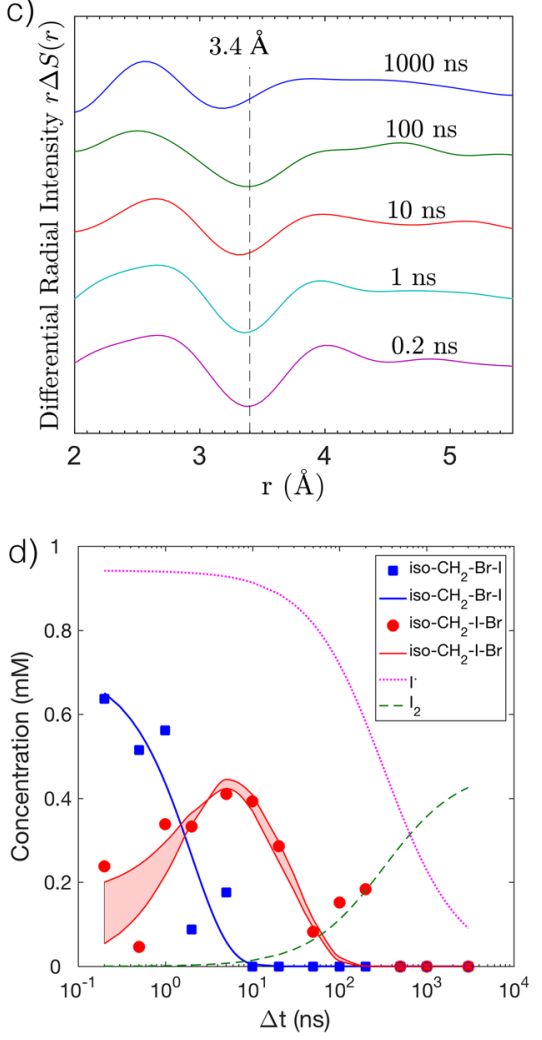

FIG. 4. (a) Difference scattering in cyclohexane for particular time-delays. The inset shows pure solvent expansion. (b) Fitting of the difference scattering. The solvent contribution was preliminarily subtracted. Dashed line indicates the first negative peak position corresponding to the depletion of distance between $\mathrm{I}$ and $\mathrm{Br}$ in the ground state of the $\mathrm{CH}_{2} \mathrm{IBr}$. (c) Real space representation of collected scattering patterns. Vertical dashed line shows the distance between $\mathrm{I}$ and $\mathrm{Br}$ atoms in the ground state of the $\mathrm{CH}_{2} \mathrm{IBr}$ molecule. The $q$-space $\rightarrow r$-space transformation details and description are in the text. (d) Kinetics of photoproducts in cyclohexane solution. Solid squares and circles are experimental values measured by X-ray scattering fits; lines are fits to kinetics equations (11), (12), and (9). Borders of the shaded band represent two solutions corresponding to various initial concentrations of $\mathrm{CH}_{2} \mathrm{I}-\mathrm{Br}$ as discussed in the main text. Concentrations of monoatomic iodine ions were calculated because these ions do not contribute to the WAXS signal. We refer the reader to Sec. II E for detailed information. facilitate the modeling. This is particularly helpful when the number of variables in the fitting could be reduced. ${ }^{11,12}$

The iodine end-product in cyclohexane is molecular $\mathrm{I}_{2}$, whereas iodine species in methanol enter a complex cascade reaction ultimately forming an $\mathrm{I}_{3}{ }^{-}$anion as the end product. We cannot follow monoatomic ions in our fitting. We can only implicitly include the disproportionation of iodine di- and triatomic ions into the fitting of the experimental data. Given the assumption that the concentration of $\mathrm{CH}_{2} \mathrm{Br}$. should change insignificantly in the $\mu$ s-time frame a)

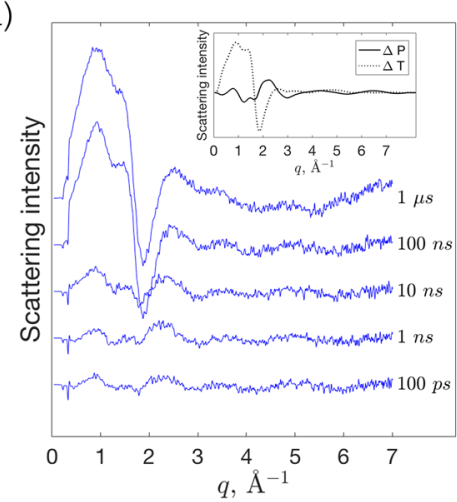

b)

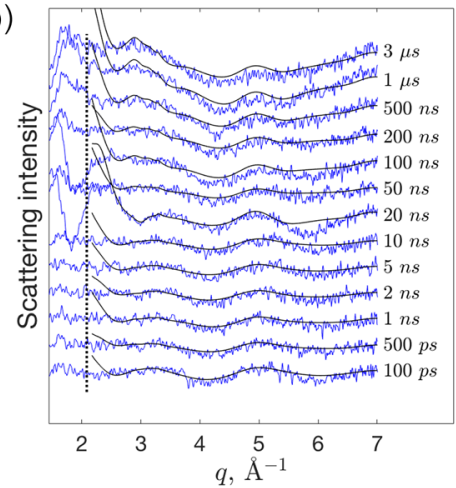

c)
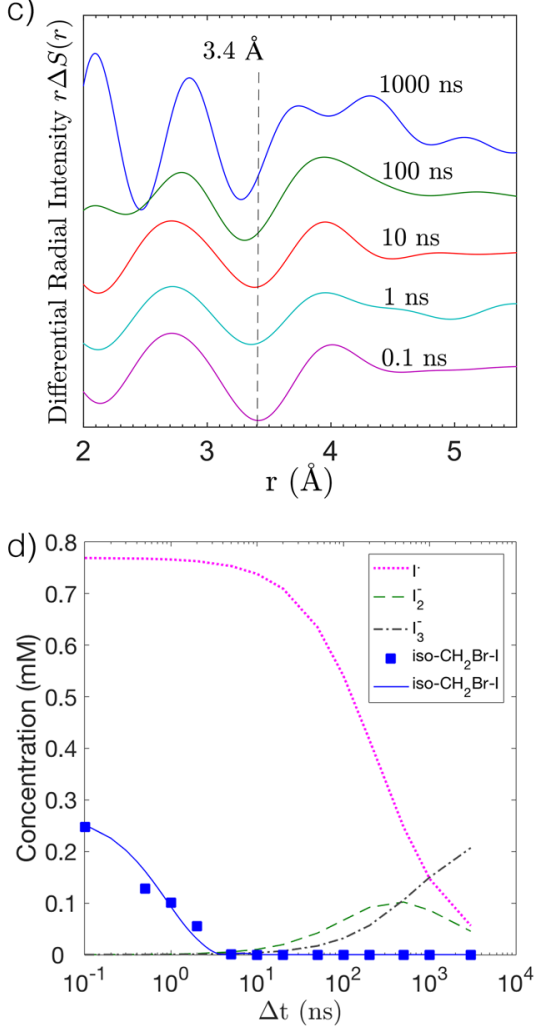

FIG. 5. (a) Difference scattering in methanol for particular time-delays. The inset shows pure solvent expansion. (b) Fitting of the difference scattering. The solvent contribution was preliminarily subtracted; however, later analysis shows the residual contribution of the solvent in the signal. Dashed line indicates the first negative peak position corresponding to the depletion of distance between $\mathrm{I}$ and $\mathrm{Br}$ in the ground state of $\mathrm{CH}_{2} \mathrm{IBr}$. (c) Real space representation of collected scattering patterns. Vertical dashed line shows the distance between $\mathrm{I}$ and $\mathrm{Br}$ atoms in the ground state of the $\mathrm{CH}_{2} \mathrm{IBr}$ molecule. (d) Kinetics of photoproducts in methanol solution. Solid squares are experimental values measured by X-ray scattering fits; lines are fits to kinetics equations. We do not directly observe in the X-ray scattering the contributions from I. We estimated the concentration of $\mathrm{I}_{3}{ }^{-}$at the longest time-delays and we back traced following its kinetic equation. The concentration of $\mathrm{I}_{2}{ }^{-}$was computed by knowing the concentration of $\mathrm{I}_{3}{ }^{-}$and the diffusion rate of $\mathrm{I}$ in methanol. We refer the reader to Sec. II E for the taken assumptions. $\mathrm{CH}_{2} \mathrm{Br}-\mathrm{I}$ decays with an estimated lifetime of $\approx 0.9$ ns. 
and the absence of structural isomers of $\mathrm{CH}_{2} \mathrm{IBr}$ at the $\mu \mathrm{s}$ time scale, ${ }^{11,12}$ we have fitted the microsecond time delays $(0.5 \mu \mathrm{s}, 1 \mu \mathrm{s}$, and $3 \mu \mathrm{s})$ assuming only the $\mathrm{CH}_{2} \mathrm{Br} \cdot$ and $\mathrm{I}_{2}$ contribution to the differential $\mathrm{X}$-ray scattering in cyclohexane, and, respectively, $\mathrm{CH}_{2} \mathrm{Br}$. and $\mathrm{I}_{3}{ }^{-}$in methanol. Fitted average concentration of the $\mathrm{CH}_{2} \mathrm{Br}$. was backpropagated and kept constant for all the time delays. Concentrations of $\mathrm{I}_{2}$ in cyclohexane and $\mathrm{I}_{3}{ }^{-}$in methanol were backpropagated based on the respective reaction model for every system. Furthermore, the concentration of $\mathrm{I}_{2}{ }^{-}$in methanol solution was calculated based on the $\mathrm{I}_{3}{ }^{-}$concentrations and incorporated into the fitting of the experimental scattering. The reactions involving iodine species have been considered diffusion-controlled. Predicted values for diffusion rates of $\mathrm{I}$. in cyclohexane $\left(6.48 \times 10^{9} \mathrm{M}^{-1} \mathrm{~s}^{-1}\right)$ and in methanol $\left(1.10 \times 10^{10} \mathrm{M}^{-1} \mathrm{~s}^{-1}\right)$ have been used. ${ }^{12}$

Furthermore, owing to the weak halogen-halogen bond, we have tested the breaking of the initially formed $\mathrm{CH}_{2} \mathrm{Br}-\mathrm{I}$ to $\mathrm{CH}_{2} \mathrm{Br}$. and $\mathrm{I}$. The incorporation of this reaction into the fitting does not significantly improve it. This result can be partially explained by the poor signal-to-noise ratio of the collected data at high $q$. Moreover, the outcome of this modified fitting does not alter the main conclusions about which isomers are formed and how they decay, despite a small increase of the initial concentrations of isomers, which is compensated by a large estimated error of about $10 \%$ in the determination of the concentrations. Albeit the formation of $\mathrm{CH}_{2} \mathrm{Br}$. and I. is a probable decay channel for the $\mathrm{CH}_{2} \mathrm{Br}-\mathrm{I}$ isomer, similarly to the work of Vincent et al. ${ }^{12}$ for the $\mathrm{CH}_{2} \mathrm{I}-\mathrm{I}$, we could only implicitly follow this process and could not recover a conversion rate of this process, unlikely for the decay of the $\mathrm{CH}_{2} \mathrm{Br}-\mathrm{I}$ isomer to the ground state. Therefore, we oversimplified our model to reject any breaking and releasing of I from $\mathrm{CH}_{2} \mathrm{Br}-\mathrm{I}$.

Therefore, the fate of I species in cyclohexane is kinetically fitted by the following kinetic equations:

$$
\mathrm{I} \cdot+\mathrm{I} \cdot \stackrel{r_{1}}{\longrightarrow} \mathrm{I}_{2}, \quad r_{1}=k_{1}\left([\mathrm{I} \cdot]^{2}\right) .
$$

In polar solvent, the I species go through a disproportionation reaction, as Rowley and Meyer have exhaustively characterized in acetonitrile, ${ }^{103}$ such that the following equations are valid:

$$
\begin{array}{r}
\mathrm{I} \cdot+\mathrm{I}^{-} \stackrel{r_{2}}{\longrightarrow} \mathrm{I}_{2}{ }^{-}, \quad r_{2}=k_{2}\left([\mathrm{I} \cdot]^{2}\right), \\
\mathrm{I}_{2}{ }^{-}+\mathrm{I} \cdot \stackrel{r_{3}}{\longrightarrow} \mathrm{I}_{2}{ }^{-}, \quad r_{3}=k_{3}\left(\left[\mathrm{I}_{2}{ }^{-}\right][\mathrm{I} \cdot]\right),
\end{array}
$$

where, in both models, $r_{i}$ and $k_{i}$ are the recombination and diffusion rate constants.

To eliminate the possibility of $\mathrm{Br}$ ions or radicals in solution, we avoided the double-photon excitation by stretching the laser pulse in the time-domain from fs to ps. As previously reported, double-photon excitation can break the $\mathrm{C}-\mathrm{Br}$ bond. Moreover, our current light absorption experiments do not show any activity of $\mathrm{C}-\mathrm{Br}$ absorption band at the laser wavelength $267 \mathrm{~nm}$, Fig. 2. Therefore, we assume that no bromine $\mathrm{Br}$ - radicals should be observed directly after the excitation, and no accumulation of $\mathrm{Br}_{2}$ molecules is expected in the solution.
The experimental concentrations of the $\mathrm{CH}_{2} \mathrm{Br}-\mathrm{I}$ calculated from the $\mathrm{X}$-ray scattering were fitted versus the kinetics equations (11) and (12),

$$
\begin{gathered}
{\left[C_{\mathrm{CH}_{2} \mathrm{Br}-\mathrm{I}}\right]=\left[C_{0}\right] e^{-t / \tau_{1}},} \\
{\left[C_{\mathrm{CH}_{2} \mathrm{I}-\mathrm{Br}}\right]=\left[C_{0}\right] \frac{\tau_{2}}{\tau_{1}-\tau_{2}}\left(e^{-t / \tau_{1}}-e^{-t / \tau_{2}}\right)+\left[C_{1}\right] e^{-t / \tau_{2}},}
\end{gathered}
$$

where $\left[\mathrm{C}_{0}\right]$ and $\left[\mathrm{C}_{1}\right]$ are concentrations of $\mathrm{CH}_{2} \mathrm{Br}-\mathrm{I}$ and $\mathrm{CH}_{2} \mathrm{I}-$ $\mathrm{Br}$ formed directly after laser flash, and $\tau_{1}$ and $\tau_{2}$ are their respective lifetimes. Equations (11) and (12) hold for the cyclohexane solution, whereas Eq. (11) holds for the methanol solution. The minimization has been done in terms of $\chi^{2}$ between experimental and theoretical concentrations.

\section{RESULTS AND DISCUSSION}

\section{A. Kinetics of photoproduct species in cyclohexane}

Time-resolved data were collected for $\Delta \mathrm{t}=0.2,0.5,1,2$, 5, 10, 20, 50, 100, 200, 500, 1000, and 3000 ns, Figs. 4(a) and 4(b). The signal associated with the solvent [inset in Fig. 4(a)] was subtracted from the dataset. Remaining signal was fitted with theoretical X-ray differential scattering calculated from structures of solute molecules, Fig. 4(b).

Concentrations of photoproduct species were recovered from the fitting of the WAXS spectra at different time-delays, Fig. $4(\mathrm{~d})$. The results indicate the formation of the $\mathrm{CH}_{2} \mathrm{Br}-\mathrm{I}$ isomer at short time delay and subsequently decays. The signal at nanosecond time delay shifted toward the shorter $\mathrm{I}-\mathrm{Br}$ bond distance, as can be seen in the real-space representation, Fig. 4(c). We have assigned this signal to the formation of the structural isomer $\mathrm{CH}_{2} \mathrm{I}-\mathrm{Br}$. This assumption is made on the basis of quantum mechanical calculations giving nearly $0.2 \AA$ shorter I- $\mathrm{Br}$ bond-distance in $\mathrm{CH}_{2} \mathrm{I}-\mathrm{Br}$ compared to $\mathrm{CH}_{2} \mathrm{Br}-\mathrm{I}$. The other halogen species such as $\mathrm{I}_{2}$ or $\mathrm{IBr}$ also have shorter bond length compared to the $\mathrm{Br}-\mathrm{I}$ bond length in $\mathrm{CH}_{2} \mathrm{Br}-\mathrm{I}$. However, these species are formed due to a slow non-geminate recombination; thus, they cannot contribute to the scattering at a nanosecond time scale.

Formation of halogen-atom complexes with parent organo-halides has been reported, for example, by Alfassi et al. ${ }^{104}$ in several solutions for $\mathrm{Br}$ atoms, and Preston et al. ${ }^{105}$ in the photoisomerization of $\mathrm{CHBr}_{3}$ and $\mathrm{CHI}_{3}$. In this work, no complex was introduced to the fitting. Indeed, complexes should have lifetimes in the time scale measured in the current experiment, yet we assumed that the differential scattering signal from these complexes will not significantly contribute to the total scattering difference signal due to their small concentration. Additionally, for instance, the structure of $\mathrm{I} \cdot \mathrm{CH}_{2} \mathrm{Br}$. should closely resemble that of the ground-state $\mathrm{CH}_{2} \mathrm{BrI}$, whereas the $\mathrm{I}-\mathrm{I}$ bond distance in $\mathrm{I}-\mathrm{CH}_{2} \mathrm{IBr}$ is close to the distances between iodine in $\mathrm{I}_{2}$. Thus, complexes $\mathrm{I}-\mathrm{CH}_{2} \mathrm{IBr}$ nor I. $\mathrm{CH}_{2} \mathrm{Br}$ were ruled out from the analysis, in a similar way as iodine complexes potentially formed in the $\mathrm{CH}_{2} \mathrm{I}_{2}$ system earlier investigated. ${ }^{12}$

Striking feature in the kinetics of $\mathrm{CH}_{2} \mathrm{I}-\mathrm{Br}$ is an observable maximum at around $5 \mathrm{~ns}$. The rise in the concentration of $\mathrm{CH}_{2} \mathrm{I}-\mathrm{Br}$ roughly correlates with a depletion of $\mathrm{CH}_{2} \mathrm{Br}-\mathrm{I}$, suggesting a conversion from $\mathrm{CH}_{2} \mathrm{Br}-\mathrm{I}$ to $\mathrm{CH}_{2} \mathrm{I}-\mathrm{Br}$. This 
conversion was earlier found by Anderson et al. ${ }^{83}$ supporting the hypothesis of isomer conversion at our experimental conditions. This allows us to further incorporate the conversion rate into the fitting. It turned out that the fitting function has a trade-off between the initially formed $\mathrm{CH}_{2} \mathrm{I}-\mathrm{Br}$ isomer and the rate of conversion from $\mathrm{CH}_{2} \mathrm{Br}-\mathrm{I}$ to $\mathrm{CH}_{2} \mathrm{I}-\mathrm{Br}$. Particularly, we found the global minimum of the $\chi^{2}$ function when we assume that $\mathrm{CH}_{2} \mathrm{I}-\mathrm{Br}$ is the initially formed with a concentration of $0.16 \mathrm{mM}$, and $\approx 30 \%$ conversion rate from $\mathrm{CH}_{2} \mathrm{Br}-\mathrm{I}$ to $\mathrm{CH}_{2} \mathrm{I}-\mathrm{Br}$ [an upper bond of the shaded band in Fig. 4(d)]. Furthermore, we tested the hypothesis of no initially formed $\mathrm{CH}_{2} \mathrm{I}-\mathrm{Br}$ (an assumption based on the observation that absorption bands for $\mathrm{C}-\mathrm{I}$ and $\mathrm{C}-\mathrm{Br}$ bonds do not overlap). For this latter case, the fitting returns a conversion rate such that $75 \%$ of $\mathrm{CH}_{2} \mathrm{Br}-\mathrm{I}$ converts to $\mathrm{CH}_{2} \mathrm{I}-\mathrm{Br}$ [lower bond of the shaded band in Fig. 4(d)]. Anderson et al. ${ }^{83}$ reported a ratio of 2.8:1 between initially formed $\mathrm{CH}_{2} \mathrm{Br}-\mathrm{I}$ and $\mathrm{CH}_{2} \mathrm{I}-\mathrm{Br}$ within the $100 \mathrm{ps}$ timedelay and $10 \%$ for intra-isomerization yields. Thus, our fitting outcome yielding a 4:1 ratio between $\mathrm{CH}_{2} \mathrm{Br}-\mathrm{I}$ and $\mathrm{CH}_{2} \mathrm{I}-\mathrm{Br}$ at time below $200 \mathrm{ps}$, and $30 \%$ for intra-isomerization between $\mathrm{CH}_{2} \mathrm{Br}-\mathrm{I}$ and $\mathrm{CH}_{2} \mathrm{I}-\mathrm{Br}$ correlate with the earlier observations of isomer formation and reorganisation. Fitting results are tabulated in Table II.

The presence of $\mathrm{CH}_{2} \mathrm{I}-\mathrm{Br}$ in solution has been reported by Zheng et al. ${ }^{72,77}$ upon UV excitation at $\lambda_{0}=253 \mathrm{~nm}$ and $\lambda_{1}=239 \mathrm{~nm}$. At these wavelengths, both chromophores are excited with preference for the $\mathrm{C}-\mathrm{Br}$ chromophore, leading to $\mathrm{CH}_{2} \mathrm{I}-\mathrm{Br}$. A possible channel for the creation of $\mathrm{CH}_{2} \mathrm{I}-$ $\mathrm{Br}$ is the rapid isomerization of promptly formed $\mathrm{CH}_{2} \mathrm{Br}-\mathrm{I}$ which is less energetically stable than $\mathrm{CH}_{2} \mathrm{I}-\mathrm{Br}$. There are few reports of photo-excitation at $267 \mathrm{~nm}$. Tarnovsky et al. ${ }^{78}$ did not observe $\mathrm{CH}_{2} \mathrm{I}-\mathrm{Br}$ in acetonitrile because their experiment was limited to ultra-short time delays. Tang et al. ${ }^{79}$ did observe $\mathrm{CH}_{2} \mathrm{I}-\mathrm{Br}$ in butanol upon UV excitation at $\lambda_{2}$ $=271 \mathrm{~nm}$ after $6 \mathrm{~ns}$ from the laser flash. Anderson et al. ${ }^{83}$ probed a similar cyclohexane solution, at a time window from $1 \mathrm{ps}$ to $3000 \mathrm{ps}$, and they observed the presence of both isomers. $\mathrm{CH}_{2} \mathrm{I}-\mathrm{Br}$ was found to be formed in the solution at 50 ps after cleavage. Its formation is, however, not clearly defined in their data. Among the several pathways for the formation of these isomers, the authors first propose that the cleavage of the $\mathrm{C}-\mathrm{Br}$ bond can occur at the initial photolysis step, giving rise, with the same modality, to the observed isomer: for example, Attar et al. ${ }^{106}$ found that a minor fraction of $\mathrm{C}-\mathrm{I} / \mathrm{C}-\mathrm{Br}$ cleavage (ratio 4.8:1) occurs in gas phase at $266 \mathrm{~nm}$ wavelength. The alternative pathways for the isomer formation are either by recombination of the geminate $\mathrm{I}^{-} \mathrm{CH}_{2} \mathrm{Br}^{+}$or by isomerization of the initial hot $\mathrm{CH}_{2} \mathrm{Br}-\mathrm{I}$ product. The decay mechanism of $\mathrm{CH}_{2} \mathrm{Br}-\mathrm{I}$ can be both

TABLE II. Calculated concentration at $\Delta t=0$ of photoproducts and their lifetimes. The lifetimes of $\mathrm{CH}_{2} \mathrm{Br}$. have been kept constant in the fitting of $\mathrm{X}$-ray data, that is, lifetime is infinite.

\begin{tabular}{lcc}
\hline \hline Photoproducts & Concentration & Lifetime (ns) \\
\hline & $(\Delta t=0, \mathrm{mM})$ & \\
$\mathrm{CH}_{2} \mathrm{Br} \cdot \mathrm{I} \cdot$ & 0.942 & $+\infty$ \\
$\mathrm{CH}_{2} \mathrm{Br}-\mathrm{I}$ & 0.719 & 1.9 \\
$\mathrm{CH}_{2} \mathrm{I}-\mathrm{Br}$ & $0-0.16$ & 31 \\
\hline \hline
\end{tabular}

unimolecular and bimolecular. The other origin of the $\mathrm{CH}_{2} \mathrm{I}-$ $\mathrm{Br}$ at an early time-delay can be due to the solvent modifying the branching ratio between the $\mathrm{C}-\mathrm{I}$ and $\mathrm{C}-\mathrm{Br}$ cleavage. The solvent could catalyze the re-isomerization of $\mathrm{CH}_{2} \mathrm{Br}-$ $\mathrm{I} \longrightarrow \mathrm{CH}_{2} \mathrm{I}-\mathrm{Br}$ due to either some insertion process or three-member ring-type transition state which could favor the counter-isomerization of $\mathrm{CH}_{2} \mathrm{Br}-\mathrm{I}$ to $\mathrm{CH}_{2} \mathrm{I}-\mathrm{Br} .{ }^{107}$

Thus, our findings support the hypothesis of reisomerization of $\mathrm{CH}_{2} \mathrm{Br}-\mathrm{I} \longrightarrow \mathrm{X} \longrightarrow \mathrm{CH}_{2} \mathrm{I}-\mathrm{Br}$, based on the peaking of $\mathrm{CH}_{2} \mathrm{I}-\mathrm{Br}$ concentration at $\approx 10 \mathrm{~ns}$, and the lifetimes of both isomers.

\section{B. Kinetics of photoproduct species in methanol}

Time-resolved WAXS studies of $\mathrm{CH}_{2} \mathrm{IBr}$ in methanol were also performed. The data are collected at $\Delta \mathrm{t}=0.1,0.5,1$, 2, 5, 10, 20, 50, 100, 200, 500, 1000, and 3000 ns, Fig. 5(a). Data analysis in this specific case follows the one of $\mathrm{CH}_{2} \mathrm{IBr}$ in cyclohexane according to the model previously introduced. The methanol signal contributes significantly at large $q$ [see the inset of Fig. 5(a)] with respect to the cyclohexane solution [Fig. 4(a), inset]. Thus, small errors in defining scattering contribution significantly change the result at wide scattering angles. For a fitting of photochemically excited species, the signal of the solvent was subtracted from every experimental differential X-ray scattering [Fig. 5(b)]. However, we noticed a possible small residual contribution of the solvent in this signal. Due to this fact, the solvent components were used in the fitting on Fig. 5(b) alongside with a solute scattering.

The fitted kinetics are plotted in Fig. 5(d). Fitting of the signal, Fig. 5(b), and inspection of the signal in the real-space, Fig. 5(c), suggest the formation of the $\mathrm{CH}_{2} \mathrm{Br}-\mathrm{I}$ isomer. The concentration of the initially formed isomer in methanol is smaller than that in cyclohexane. The fitting returns an initial $\mathrm{CH}_{2} \mathrm{Br}-\mathrm{I}$ concentration of $0.28 \mathrm{mM}$ and a lifetime of $0.9 \mathrm{~ns}$. The initial concentration of $\mathrm{CH}_{2} \mathrm{Br}$. has been estimated to about $0.77 \mathrm{mM}$.

The experimental lifetime is comparable with the aforementioned experiments of $\mathrm{CH}_{2} \mathrm{IBr}$ in polar solvents. In analogy with $\mathrm{CH}_{2} \mathrm{I}-\mathrm{I}$, the more rapid decay of $\mathrm{CH}_{2} \mathrm{Br}-\mathrm{I}$ might be caused by a destabilization and dissociation of the $\mathrm{Br}-\mathrm{I}$ bond through a specific solvation and electron transfer, ${ }^{40,58}$ such as $\mathrm{CH}_{2} \mathrm{Br}-\mathrm{I} \longrightarrow \mathrm{CH}_{2} \mathrm{Br}^{+}+\mathrm{I}^{-}$. Nevertheless, we did not include this pathway in our kinetic model because the kinetic fitting did not improve with respect to a more simple one. Moreover, we cannot clearly fit $\mathrm{CH}_{2} \mathrm{Br}^{+}$at short time delay, because that specie is a weak X-ray scatterer. The reaction of the photoproducts can be even more complicated as El-Khoury et al. for iodoform, ${ }^{108} \mathrm{Kwok}$ et al. ${ }^{109}$ and Tarnovsky et al. ${ }^{58}$ for $\mathrm{CH}_{2} \mathrm{I}_{2}$, and $\mathrm{Kwok}$ et al. for $\mathrm{CH}_{2} \mathrm{Br}_{2}$ and $\mathrm{CHBr}_{3}$ in water solution, ${ }^{110,111}$ and Du et al. ${ }^{81}$ and Lin et al. ${ }^{82}$ for $\mathrm{CH}_{2} \mathrm{IBr}$ in water solution have shown. In these latter cases, the reaction goes through a complicate mechanism of $\mathrm{OH}$ moiety insertion,

$$
\begin{aligned}
& \text { - } \mathrm{CH}_{2} \mathrm{Br}-\mathrm{I}+\mathrm{H}_{2} \mathrm{O} \longrightarrow \mathrm{CH}_{2} \mathrm{BrOH}+\mathrm{HI} \text {, } \\
& \text { - } \mathrm{CH}_{2} \mathrm{BrOH}+\mathrm{H}_{2} \mathrm{O} \longrightarrow \mathrm{CH}_{2}(\mathrm{OH})_{2}+\mathrm{HBr} \text {, }
\end{aligned}
$$

with the elimination of the halogens. 
Methanol is less polar than water and slightly more acidic than water. In such a case, the reaction looks more complex and the detection of intermediate and final structures (for example, $\mathrm{HI}, \mathrm{HBr}$, and $\mathrm{CH}_{3}-\mathrm{O}-\mathrm{CH}_{2}-\mathrm{O}-\mathrm{CH}_{3}$, similarly to the complex pathway for the UV photolysis of $\mathrm{CH}_{2} \mathrm{I}_{2}$ in methanol ${ }^{112,113}$ ) is complicated by the small scattering contribution to the $\mathrm{X}$ ray patterns of the scattering centers and it was not taken into account.

\section{CONCLUSIONS}

The recombination of $\mathrm{CH}_{2} \mathrm{IBr}$ upon $\mathrm{UV}$ photodissociation of the $\mathrm{C}-\mathrm{I}$ chromophore has been investigated by using TR-WAXS both in polar (methanol) and in non-polar (cyclohexane) solvents. These measurements bridge the gap between previous ps-time-resolved and ns-time-resolved experiments on $\mathrm{CH}_{2} \mathrm{IBr}$ photolysis experiments, and they are the first measurements of $\mathrm{CH}_{2} \mathrm{IBr}$ photochemical reaction in methanol solution. In particular, in this report, we clearly show both the formation and decay of the transient isomer $\mathrm{CH}_{2} \mathrm{I}-\mathrm{Br}$, which in cyclohexane is formed by an internal reorganization of $\mathrm{CH}_{2} \mathrm{Br}-\mathrm{I}$, and where the different structural nature of the intermediates is confirmed by a structural method. In methanol, $\mathrm{CH}_{2} \mathrm{I}-\mathrm{Br}$ is not observed and the lifetime of $\mathrm{CH}_{2} \mathrm{Br}-\mathrm{I}$ is shorter ( $0.9 \mathrm{~ns}$ with respect to $1.9 \mathrm{~ns}$ in cyclohexane). The lifetime of $\mathrm{CH}_{2} \mathrm{I}-\mathrm{Br}$ in cyclohexane is about $30 \mathrm{~ns}$, whereas the one of $\mathrm{CH}_{2} \mathrm{Br}-\mathrm{I}$ is about $2 \mathrm{~ns}$. Thus the energy ordering is such that $\mathrm{CH}_{2} \mathrm{Br}-\mathrm{I}>\mathrm{CH}_{2} \mathrm{I}-\mathrm{Br}>\mathrm{CH}_{2} \mathrm{BrI}$ as it is evidenced that, following our model, $\mathrm{CH}_{2} \mathrm{Br}-\mathrm{I}$ goes on to form $\mathrm{CH}_{2} \mathrm{I}-\mathrm{Br}$ which in turn forms $\mathrm{CH}_{2} \mathrm{BrI}$. We want to remind that the lifetime depends on the energy barrier between the minima of the ground states. The reaction pathways and yields are summarized in Fig. 6.

A small fraction of $\mathrm{CH}_{2} \mathrm{I}-\mathrm{Br}$ is probably formed in the sub-200 ps time delays after the laser excitation. We cannot estimate an unequivocal conversion rate from $\mathrm{CH}_{2} \mathrm{Br}-\mathrm{I}$ to $\mathrm{CH}_{2} \mathrm{I}-\mathrm{Br}$. If we assume that in cyclohexane no $\mathrm{CH}_{2} \mathrm{I}-\mathrm{Br}$ is initially formed, the conversion rate from $\mathrm{CH}_{2} \mathrm{Br}-\mathrm{I}$ to $\mathrm{CH}_{2} \mathrm{I}-\mathrm{Br}$ is unphysical, about 75\%. Like Anderson et al., our global fit shows that $\mathrm{CH}_{2} \mathrm{I}-\mathrm{Br}$ is already formed at $t=0$, although we want to stress that we should not be able to excite the $\mathrm{C}-\mathrm{Br}$ chromophore with photons at $267 \mathrm{~nm}$. In this case, we estimate the $\approx 30 \%$ of $\mathrm{CH}_{2} \mathrm{Br}-\mathrm{I}$ decays to $\mathrm{CH}_{2} \mathrm{I}-\mathrm{Br}$. We stress that our results are based on the input structures of the isomers,

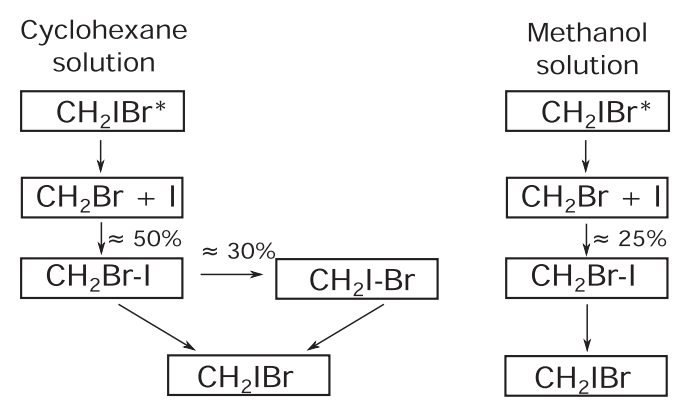

FIG. 6. Resulting pathways of the relaxation of promptly formed $\mathrm{CH}_{2} \mathrm{Br}-\mathrm{I}$ in cyclohexane and methanol. An initial concentration of $0.16 \mathrm{mM}$ of $\mathrm{CH}_{2} \mathrm{I}-\mathrm{Br}$ was assumed in cyclohexane. The solvent polarity plays the role to stabilize isomers and funnel the reactions. particularly the bond length between I-Br. Yet, the two different geometrical isomers are resolved by a structural method such as TR-WAXS, showing its sensitivity to sub-angstrom distances.

The $\mathrm{CH}_{2} \mathrm{Br}-\mathrm{I}$ to $\mathrm{CH}_{2} \mathrm{I}-\mathrm{Br}$ pathway could not be confirmed by quantum chemistry calculations that were based on optimized ground state geometries, but we believe that further exploration of the excited states might reveal possible reaction pathways. The pathway is clearly solvent-dependent, and the solvent mediates the reaction with some sort of geometrical insertion or three member reactions. We carried out our experiment at very diluted concentration, lower than the one of our experiment on $\mathrm{CH}_{2} \mathrm{I}_{2}$. This condition allows us to reject the hypothesis of generation of complexes between the reactive iodine and $\mathrm{CH}_{2} \mathrm{Br}$, for example. At high concentration of the solute, iodine complexes with either the solvent or solute could appear in solution and should be considered while fitting the X-ray differential scattering. These will change the kinetic model, especially for what regards the molecular iodine species that are the final observable and stable molecules.

\section{ACKNOWLEDGMENTS}

J. Davidsson and R. Neutze are supported by the Swedish Science Research Council (VR).

D. van der Spoel is supported by the Swedish Research Council (VR), and this work is supported by the Swedish Strategic Research Programme.

All calculations were performed on resources provided by the Swedish National Infrastructure for Computing (SNIC) at the Uppsala Multidisciplinary Center for Advanced Computational Science (UPPMAX) and at the High Performance Computing Center North (HPC2N).

The cyclohexane solvent heating and expansion datasets were collected by C. Gilles and F. Ewald from ID09B.

M.M. would like to acknowledge Dr. S. Deville (@DevilleSy), Dr. G. Discepoli (@gd_roger), and Dr. C. Noirjean for fruitful comments.

A.N. would like to acknowledge Dr. I. Fdez. Galván for temptative calculations of quantum chemistry transition states.

These experiments were performed on the ID09B beamline at the European Synchrotron Radiation Facility (ESRF), Grenoble, France. We are grateful to the Local Contact at ESRF (Dr. M. Wulff) for providing assistance in using such a beamline.

${ }^{1}$ H. Ihee, M. Wulff, J. Kim, and S.-I. Adachi, Int. Rev. Phys. Chem. 29, 453 (2010).

${ }^{2}$ J. Kim, K. H. Kim, J. H. Lee, and H. Ihee, Acta Crystallogr., Sect. A: Found. Crystallogr. 66, 270 (2010).

${ }^{3}$ J. Lee and H. Ihee, Struct. Chem. 21, 37 (2010).

${ }^{4}$ R. Neutze and K. Moffat, Curr. Opin. Struct. Biol. 22, 651 (2012).

${ }^{5}$ R. Neutze, Philos. Trans. R. Soc. London, Ser. B 369, 20130318 (2014).

${ }^{6}$ S.-I. Adachi and H. Ihee, in X-Ray Free Electron Lasers: Applications in Materials, Chemistry and Biology, edited by U. Bergmann, V. Yachandra, and J. Yano (The Royal Society of Chemistry, 2017), pp. 264-283.

${ }^{7}$ T. K. Kim, M. Lorenc, J. H. Lee, M. Lo Russo, J. Kim, M. Cammarata, Q. Kong, S. Noel, A. Plech, M. Wulff, and H. Ihee, Proc. Natl. Acad. Sci. U. S. A. 103, 9410 (2006). 
8 J. H. Lee, J. Kim, M. Cammarata, Q. Kong, K. H. Kim, J. Choi, T. K. Kim, M. Wulff, and H. Ihee, Angew. Chem., Int. Ed. 47, 1047 (2008).

${ }^{9}$ C. W. Ahn, H. Ki, J. Kim, J. Kim, S. Park, Y. Lee, K. H. Kim, Q. Kong, J. Moon, M. N. Pedersen, M. Wulff, and H. Ihee, J. Phys. Chem. Lett. 9, 647 (2018).

${ }^{10}$ Q. Kong, M. Wulff, J. H. Lee, S. Bratos, and H. Ihee, J. Am. Chem. Soc. 129, 13584 (2007).

${ }^{11}$ J. Davidsson, J. Poulsen, M. Cammarata, P. Georgiou, R. Wouts, G. Katona, F. Jacobson, A. Plech, M. Wulff, G. Nyman, and R. Neutze, Phys. Rev. Lett. 94, 245503 (2005).

${ }^{12} \mathrm{~J}$. Vincent, M. Andersson, M. Eklund, A. B. Wohri, M. Odelius, E. Malmerberg, Q. Kong, M. Wulff, R. Neutze, and J. Davidsson, J. Chem. Phys. 130, 154502 (2009).

${ }^{13}$ A. Plech, M. Wulff, S. Bratos, F. Mirloup, R. Vuilleumier, F. Schotte, and P. A. Anfinrud, Phys. Rev. Lett. 92, 125505 (2004).

${ }^{14}$ S. Bratos, F. Mirloup, R. Vuilleumier, M. Wulff, and A. Plech, Chem. Phys. 304, 245 (2004)

${ }^{15}$ S. Bratos, M. Wulff, J.-C. Leicknam, and Q. Kong, Chem. Phys. Lett. 619, 88 (2015).

${ }^{16}$ R. Neutze, R. Wouts, S. Techert, J. Davidsson, M. Kocsis, A. Kirrander, F. Schotte, and M. Wulff, Phys. Rev. Lett. 87, 195508 (2001)

${ }^{17}$ Q. Kong, J. H. Lee, M. Lo Russo, T. K. Kim, M. Lorenc, M. Cammarata, S. Bratos, T. Buslaps, V. Honkimaki, H. Ihee, and M. Wulff, Acta Crystallogr., Sect. A: Found. Crystallogr. 66, 252 (2010).

${ }^{18}$ K. H. Kim, H. Ki, K. Y. Oang, S. Nozawa, T. Sato, J. Kim, T. K. Kim, J. Kim, S.-I. Adachi, and H. Ihee, ChemPhysChem 14, 3687 (2013).

${ }^{19}$ K. H. Kim, J. H. Lee, J. Kim, S. Nozawa, T. Sato, A. Tomita, K. Ichiyanagi, H. Ki, J. Kim, S.-I. Adachi, and H. Ihee, Phys. Rev. Lett. 110, 165505 (2013).

${ }^{20}$ M. Cammarata, M. Levantino, F. Schotte, P. A. Anfinrud, F. Ewald, J. Choi, A. Cupane, M. Wulff, and H. Ihee, Nat. Methods 5, 881 (2008).

${ }^{21}$ K. H. Kim, S. Muniyappan, K. Y. Oang, J. G. Kim, S. Nozawa, T. Sato, S.-Y. Koshihara, R. Henning, I. Kosheleva, H. Ki, Y. Kim, T. W. Kim, J. Kim, S.-I. Adachi, and H. Ihee, J. Am. Chem. Soc. 134, 7001 (2012)

${ }^{22}$ K. Y. Oang, K. H. Kim, J. Jo, Y. Kim, J. G. Kim, T. W. Kim, S. Jun, J. Kim, and H. Ihee, Chem. Phys. 442, 137 (2014), papers from the 11th International Conference on Femtochemistry (FEMTO11) that took place at The Technical University of Denmark (DTU), Copenhagen.

${ }^{23}$ K. Y. Oang, J. G. Kim, C. Yang, T. W. Kim, Y. Kim, K. H. Kim, J. Kim, and H. Ihee, J. Phys. Chem. Lett. 5, 804 (2014).

${ }^{24}$ T. W. Kim, J. G. Kim, C. Yang, H. Ki, J. Jo, and H. Ihee, Bull. Korean Chem. Soc. 35, 697 (2014)

${ }^{25}$ M. Levantino, G. Schirò, H. T. Lemke, G. Cottone, J. M. Glownia, D. Zhu, M. Chollet, H. Ihee, A. Cupane, and M. Cammarata, Nat. Commun. 6, 6772 (2015)

${ }^{26}$ M. Andersson, E. Malmerberg, S. Westenhoff, G. Katona, M. Cammarata, A. B. Wöhri, L. C. Johansson, F. Ewald, M. Eklund, M. Wulff, J. Davidsson, and R. Neutze, Structure 17, 1265 (2009).

${ }^{27}$ S. Ahn, K. Kim, Y. Kim, J. Kim, and H. Ihee, J. Phys. Chem. B 113, 13131 (2009)

${ }^{28}$ H. S. Cho, N. Dashdorj, F. Schotte, T. Graber, R. Henning, and P. Anfinrud, Proc. Natl. Acad. Sci. U. S. A. 107, 7281 (2010).

${ }^{29}$ S. Westenhoff, E. Nazarenko, E. Malmerberg, J. Davidsson, G. Katona, and R. Neutze, Acta Crystallogr., Sect. A: Found. Crystallogr. 66, 207 (2010).

${ }^{30}$ E. Malmerberg, Z. Omran, J. S. Hub, X. Li, G. Katona, S. Westenhoff, L. C. Johansson, M. Andersson, M. Cammarata, M. Wulff, D. van der Spoel, J. Davidsson, A. Specht, and R. Neutze, Biophys. J. 101, 1345 (2011).

${ }^{31}$ D. Arnlund, L. C. Johansson, C. Wickstrand, A. Barty, G. J. Williams, E. Malmerberg, J. Davidsson, D. Milathianaki, D. P. DePonte, R. L. Shoeman, D. Wang, D. James, G. Katona, S. Westenhoff, T. A. White, A. Aquila, S. Bari, P. Berntsen, M. Bogan, T. B. van Driel, R. B. Doak, K. S. Kjaer, M. Frank, R. Fromme, I. Grotjohann, R. Henning, M. S. Hunter, R. A. Kirian, I. Kosheleva, C. Kupitz, M. Liang, A. V. Martin, M. M. Nielsen, M. Messerschmidt, M. M. Seibert, J. Sjohamn, F. Stellato, U. Weierstall, N. A. Zatsepin, J. C. H. Spence, P. Fromme, I. Schlichting, S. Boutet, G. Groenhof, H. N. Chapman, and R. Neutze, Nat. Methods 11, 923 (2014).

${ }^{32}$ T. Reusch, D. D. Mai, M. Osterhoff, D. Khakhulin, M. Wulff, and T. Salditt, Phys. Rev. Lett. 111, 268101 (2013).

${ }^{33}$ K. H. Kim, J. G. Kim, K. Y. Oang, T. W. Kim, H. Ki, J. Jo, J. Kim, T. Sato, S. Nozawa, S.-I. Adachi, and H. Ihee, Struct. Dyn. 3, 043209 (2016).
${ }^{34}$ M. Cammarata, M. Lorenc, T. K. Kim, J. H. Lee, Q. Y. Kong, E. Pontecorvo, M. L. Russo, G. Schiro, A. Cupane, M. Wulff, and H. Ihee, J. Chem. Phys 124, 124504 (2006).

${ }^{35}$ P. Georgiou, J. Vincent, M. Andersson, A. B. Wohri, P. Gourdon, J. Poulsen, J. Davidsson, and R. Neutze, J. Chem. Phys. 124, 234507 (2006).

${ }^{36}$ J. H. Lee, M. Wulff, S. Bratos, J. Petersen, L. Guerin, J.-C. Leicknam, M. Cammarata, Q. Kong, J. Kim, K. B. Møller, and H. Ihee, J. Am. Chem. Soc. 135, 3255 (2013).

${ }^{37}$ H. Ihee, M. Lorenc, T. K. Kim, Q. Y. Kong, M. Cammarata, J. H. Lee, S. Bratos, and M. Wulff, Science 309, 1223 (2005).

${ }^{38}$ K. H. Kim, J. G. Kim, S. Nozawa, T. Sato, K. Y. Oang, T. W. Kim, H. Ki, J. Jo, S. Park, C. Song, T. Sato, K. Ogawa, T. Togashi, K. Tono, M. Yabashi, T. Ishikawa, J. Kim, R. Ryoo, J. Kim, H. Ihee, and S.-I. Adachi, Nature 518, 385 (2015).

${ }^{39}$ K. H. Kim, H. Ki, J. H. Lee, S. Park, Q. Kong, J. Kim, J. Kim, M. Wulff, and H. Ihee, Phys. Chem. Chem. Phys. 17, 8633 (2015).

${ }^{40}$ S. A. Reid, Int. Rev. Phys. Chem. 33, 341 (2014).

${ }^{41}$ J. C. Mossinger, D. E. Shallcross, and R. A. Cox, J. Chem. Soc., Faraday Trans. 94, 1391 (1998).

${ }^{42}$ U. N. E. P. E. E. A. Panel, Photochem. Photobiol. Sci. 5, 13 (2006).

${ }^{43}$ P. S. Liss, C. A. Marandino, E. E. Dahl, D. Helmig, E. J. Hintsa, C. Hughes, M. T. Johnson, R. M. Moore, J. M. C. Plane, B. Quack, H. B. Singh, J. Stefels, R. von Glasow, and J. Williams, "Short-lived trace gases in the surface ocean and the atmosphere," in Ocean-Atmosphere Interactions of Gases and Particles (Springer Earth System Sciences, Springer, Berlin, Heidelberg, 2014).

${ }^{44}$ R. M. Moore, M. Webb, R. Tokarczyk, and R. Wever, J. Geophys. Res. Oceans 101, 20899, https://doi.org/10.1029/96jc01248 (1996).

${ }^{45}$ G. W. Gribble, Chemosphere 52, 289 (2003).

${ }^{46} \mathrm{~W}$. Vetter, in Reviews of Environmental Contamination and Toxicology, Marine Halogenated Natural Products of Environmental Relevance edited by G. Ware, D. Whitacre, L. Albert, P. de Voogt, C. Gerba, O. Hutzinger, J. Knaak, F. Mayer, D. Morgan, D. Park, R. Tjeerdema, R. Yang, and F. Gunther (Springer New York, 2006), Vol. 188, pp. 1-57.

${ }^{47}$ K. Kotte, F. Löw, S. G. Huber, T. Krause, I. Mulder, and H. F. Schöler, Biogeosciences 9, 1225 (2012).

${ }^{48}$ F. Keng, S.-M. Phang, N. Rahman, E. Leedham, C. Hughes, A. Robinson, N. Harris, J. Pyle, and W. Sturges, J. Appl. Phycol. 25, 1377 (2013).

${ }^{49}$ H. Hepach, B. Quack, F. Ziska, S. Fuhlbrügge, E. L. Atlas, K. Krüger, I. Peeken, and D. W. R. Wallace, Atmos. Chem. Phys. 14, 1255 (2014).

${ }^{50} \mathrm{~K}$. Ballschmiter, Chemosphere 52, 313 (2003).

${ }^{51}$ C. Murphy, J. Appl. Microbiol. 94, 539 (2003).

${ }^{52}$ M. Šulka, K. Šulková, F. Louis, P. Neogrády, and I. Černušák, Z. Phys. Chem. 227, 1337 (2013)

${ }^{53}$ J. D. Méndez-Diaz, K. K. Shimabuku, J. Ma, Z. O. Enumah, J. J. Pignatello, W. A. Mitch, and M. C. Dodd, Environ. Sci. Technol. 48, 7418 (2014).

${ }^{54}$ N. J. Pienta and P. J. Kropp, J. Am. Chem. Soc. 100, 655 (1978)

${ }^{55}$ P. J. Kropp, Acc. Chem. Res. 17, 131 (1984).

${ }^{56}$ Y.-L. Li, K. H. Leung, and D. L. Phillips, J. Phys. Chem. A 105, 10621 (2001).

${ }^{57}$ D. Phillips, W. Fang, X. Zheng, Y. Li, D. Wang, and W. Kwok, Curr. Org. Chem. 8, 739 (2004)

${ }^{58}$ A. N. Tarnovsky, V. Sundström, E. Åkesson, and T. Pascher, J. Phys. Chem. A 108, 237 (2004)

${ }^{59}$ A. N. Tarnovsky, V. Sundström, E. Åkesson, and T. Pascher, J. Phys. Chem. A 109, 954 (2005).

${ }^{60}$ A. N. Tarnovsky, I. Pascher, and T. Pascher, J. Phys. Chem. A 111, 11814 (2007).

${ }^{61}$ S. J. Lee and R. Bersohn, J. Phys. Chem. 86, 728 (1982)

${ }^{62}$ L. J. Butler, E. J. Hintsa, and Y. T. Lee, J. Chem. Phys. 84, 4104 (1986).

${ }^{63}$ L. J. Butler, E. J. Hintsa, S. F. Shane, and Y. T. Lee, J. Chem. Phys. 86, 2051 (1987).

${ }^{64}$ S.-Q. Man, W. M. Kwok, and D. L. Phillips, J. Phys. Chem. 99, 15705 (1995).

${ }^{65}$ S.-Q. Man, W. M. Kwok, D. L. Phillips, and A. E. Johnson, J. Chem. Phys. 105, 5842 (1996).

${ }^{66}$ D. G. Abrashkevich, M. Shapiro, and P. Brumer, J. Chem. Phys. 116, 5584 (2002).

${ }^{67}$ K. Liu, H. Zhao, C. Wang, A. Zhang, S. Ma, and Z. Li, J. Chem. Phys. 122 044310 (2005)

${ }^{68}$ Y.-J. Liu, D. Ajitha, J. W. Krogh, A. N. Tarnovsky, and R. Lindh, ChemPhysChem 7, 955 (2006).

${ }^{69}$ A. N. Tarnovsky, J.-L. Alvarez, A. P. Yartsev, V. Sundström, and E. Åkesson, Chem. Phys. Lett. 312, 121 (1999). 
${ }^{70}$ G. Maier and H. P. Reisenauer, Angew. Chem., Int. Ed. Engl. 25, 819 (1986).

${ }^{71}$ G. Maier, H. P. Reisenauer, J. Hu, L. J. Schaad, and B. A. Hess, J. Am. Chem. Soc. 112, 5117 (1990).

${ }^{72}$ X. Zheng, W.-H. Fang, and D. L. Phillips, J. Chem. Phys. 113, 10934 (2000).

${ }^{73}$ W. M. Kwok, C. Ma, D. Phillips, A. W. Parker, M. Towrie, P. Matousek, and D. L. Phillips, Chem. Phys. Lett. 341, 292 (2001).

${ }^{74}$ I. Fdez. Galván, H.-Y. Xiao, I. Navizet, Y.-J. Liu, and R. Lindh, Mol. Phys. 112, 575 (2014).

${ }^{75}$ M. Nakamura, S.-J. Yang, P.-Y. Tsai, T. Kasai, K.-C. Lin, D.-C. Che, A. Lombardi, F. Palazzetti, and V. Aquilanti, J. Phys. Chem. A 120, 5389 (2016).

${ }^{76}$ M. Nakamura, S.-J. Yang, K.-C. Lin, T. Kasai, D.-C. Che, A. Lombardi, F. Palazzetti, and V. Aquilanti, J. Chem. Phys. 147, 013917 (2017).

${ }^{77}$ X. Zheng and D. L. Phillips, J. Chem. Phys. 113, 3194 (2000).

${ }^{78}$ A. N. Tarnovsky, M. Wall, M. Gustafsson, N. Lascoux, V. Sundström, and E. Åkesson, J. Phys. Chem. A 106, 5999 (2002).

${ }^{79}$ K.-C. Tang, J. Peng, K. G. Spears, and R. J. Sension, J. Chem. Phys. 132, 141102 (2010).

${ }^{80}$ E. V. Butaeva, A. S. Mereshchenko, M. S. Panov, and A. N. Tarnovsky, EPJ Web Conf. 41, 05012 (2013).

${ }^{81}$ Y. Du, X. Guan, W. M. Kwok, L. M. Chu, and D. L. Phillips, J. Phys. Chem. A 109, 5872 (2005).

${ }^{82}$ X. Lin, X. Guan, W. M. Kwok, C. Zhao, Y. Du, Y.-L. Li, and D. L. Phillips, J. Phys. Chem. A 109, 981 (2005).

${ }^{83}$ C. P. Anderson, K. G. Spears, K. R. Wilson, and R. J. Sension, J. Chem. Phys. 139, 194307 (2013).

${ }^{84}$ S. Bratos, J.-C. Leicknam, M. Wulff, and D. Khakhulin, J. Synchrotron Radiat. 21, 177 (2014).

${ }^{85}$ A. P. Hammersley, S. O. Svensson, M. Hanfland, A. N. Fitch, and D. Hausermann, High Pressure Res.: Int. J. 14, 235 (1996).

${ }^{86}$ A. P. Hammersley, K. Brown, W. Burmeister, L. Claustre, A. Gonzalez, S. McSweeney, E. Mitchell, J.-P. Moy, S. O. Svensson, and A. W. Thompson, J. Synchrotron Radiat. 4, 67 (1997).

${ }^{87}$ M. J. Frisch, G. W. Trucks, H. B. Schlegel, G. E. Scuseria, M. A. Robb, J. R. Cheeseman, J. A. Montgomery, Jr., T. Vreven, K. N. Kudin, J. C. Burant, J. M. Millam, S. S. Iyengar, J. Tomasi, V. Barone, B. Mennucci, M. Cossi, G. Scalmani, N. Rega, G. A. Petersson, H. Nakatsuji, M. Hada, M. Ehara, K. Toyota, R. Fukuda, J. Hasegawa, M. Ishida, T. Nakajima, Y. Honda, O. Kitao, H. Nakai, M. Klene, X. Li, J. E. Knox, H. P. Hratchian, J. B. Cross, V. Bakken, C. Adamo, J. Jaramillo, R. Gomperts, R. E. Stratmann, O. Yazyev, A. J. Austin, R. Cammi, C. Pomelli, J. W. Ochterski, P. Y. Ayala, K. Morokuma, G. A. Voth, P. Salvador, J. J. Dannenberg, V. G. Zakrzewski, S. Dapprich, A. D. Daniels, M. C. Strain, O. Farkas, D. K. Malick, A. D. Rabuck, K. Raghavachari, J. B. Foresman, J. V. Ortiz, Q. Cui, A. G. Baboul, S. Clifford, J. Cioslowski, B. B. Stefanov, G. Liu, A. Liashenko, P. Piskorz, I. Komaromi, R. L. Martin, D. J. Fox, T. Keith, M. A. Al-Laham, C. Y. Peng, A. Nanayakkara, M. Challacombe, P. M. W. Gill, B. Johnson, W. Chen, M. W. Wong, C. Gonzalez, and J. A. Pople, Gaussian 03, Revision C.02, Gaussian, Inc., Wallingford, CT, 2004.
${ }^{88}$ W. L. Jorgensen and J. Tirado-Rives, J. Am. Chem. Soc. 110, 1657 (1988).

${ }^{89}$ W. L. Jorgensen, D. S. Maxwell, and J. Tirado-Rives, J. Am. Chem. Soc. 118, 11225 (1996).

${ }^{90}$ H. Bekker, H. J. C. Berendsen, E. J. Dijkstra, S. Achterop, R. van Drunen, D. van der Spoel, A. Sijbers, H. Keegstra, B. Reitsma, and M. K. R. Renardus, in Physics Computing 92, Gromacs: A parallel computer for molecular dynamics simulations, edited by R. A. de Groot and J. Nadrchal (World Scientific, Singapore, 1993), No. 92.

${ }^{91}$ H. J. C. Berendsen, D. van der Spoel, and R. van Drunen, Comput. Phys. Commun. 91, 43 (1995).

${ }^{92}$ E. Lindahl, B. Hess, and D. van der Spoel, J. Mol. Model. 7, 306 (2001).

${ }^{93}$ D. van der Spoel, E. Lindahl, B. Hess, G. Groenhof, A. E. Mark, and H. J. C. Berendsen, J. Comput. Chem. 26, 1701 (2005).

${ }^{94}$ B. Hess, C. Kutzner, D. van der Spoel, and E. Lindahl, J. Chem. Theory Comput. 4, 435 (2008).

${ }^{95}$ A. Björling, S. Niebling, M. Marcellini, D. van der Spoel, and S. Westenhoff, J. Chem. Theory Comput. 11, 780 (2015).

${ }^{96}$ D. T. Cromer and J. T. Waber, Acta Crystallogr. 18, 104 (1965).

${ }^{97}$ D. T. Cromer and J. B. Mann, Acta Crystallogr., Sect. A: Found. Crystallogr. 24, 321 (1968).

${ }^{98}$ E. R. Henry and J. Hofrichter, in Numerical Computer Methods, Methods in Enzymology, edited by L. Brand and M. L. Johnson (Academic Press, 1992), Vol. 210, pp. 129-192.

${ }^{99}$ Q. Kong, J. H. Lee, K. H. Kim, J. Kim, M. Wulff, H. Ihee, and M. H. J. Koch, J. Am. Chem. Soc. 132, 2600 (2010).

${ }^{100}$ H. Ihee, Acc. Chem. Res. 42, 356 (2009).

${ }^{101}$ K. S. Kjær, T. B. van Driel, J. Kehres, K. Haldrup, D. Khakhulin, K. Bechgaard, M. Cammarata, M. Wulff, T. J. Sørensen, and M. M. Nielsen, Phys. Chem. Chem. Phys. 15, 15003 (2013).

${ }^{102}$ J. H. Lee, K. H. Kim, T. K. Kim, Y. Lee, and H. Ihee, J. Chem. Phys. 125, 174504 (2006).

${ }^{103}$ J. G. Rowley and G. J. Meyer, J. Phys. Chem. C 115, 6156 (2011).

${ }^{104}$ Z. B. Alfassi, R. E. Huie, J. P. Mittal, P. Neta, and L. C. T. Shoute, J. Phys. Chem. 97, 9120 (1993).

${ }^{105}$ T. J. Preston, M. A. Shaloski, and F. F. Crim, J. Phys. Chem. A 117, 2899 (2013).

${ }^{106}$ A. R. Attar, L. Piticco, and S. R. Leone, J. Chem. Phys. 141, 164308 (2014).

${ }^{107}$ P. Z. El-Khoury, S. K. Pal, A. S. Mereshchenko, and A. N. Tarnovsky, Chem. Phys. Lett. 493, 61 (2010).

${ }^{108}$ P. Z. El-Khoury, W. M. Kwok, X. Guan, C. Ma, D. L. Phillips, and A. N. Tarnovsky, ChemPhysChem 10, 1895 (2009).

${ }^{109}$ W. M. Kwok, C. Zhao, X. Guan, Y.-L. Li, Y. Du, and D. L. Phillips, J. Chem. Phys. 120, 9017 (2004).

${ }^{110}$ W. M. Kwok, C. Zhao, Y.-L. Li, X. Guan, D. Wang, and D. L. Phillips, J. Am. Chem. Soc. 126, 3119 (2004).

${ }^{111}$ W. M. Kwok, C. Zhao, Y.-L. Li, X. Guan, and D. L. Phillips, J. Chem. Phys. 120, 3323 (2004).

${ }^{112}$ W. M. Kwok, C. Ma, A. W. Parker, D. Phillips, M. Towrie, P. Matousek, and D. L. Phillips, J. Phys. Chem. A 107, 2624 (2003).

${ }^{113}$ X. Guan, X. Lin, W. M. Kwok, Y. Du, Y.-L. Li, C. Zhao, D. Wang, and D. L. Phillips, J. Phys. Chem. A 109, 1247 (2005). 